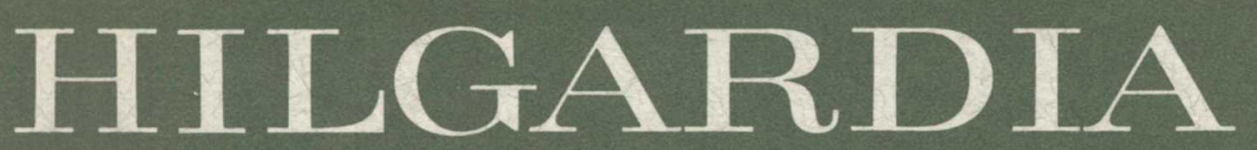

A JOURNAL OF AGRICULTURAL SCIENCE PUBLISHED BY THE CALIFORNIA AGRICULTURALEXPERIMENTSTATION

Volume 42, Number $7 \cdot$ November, 1973

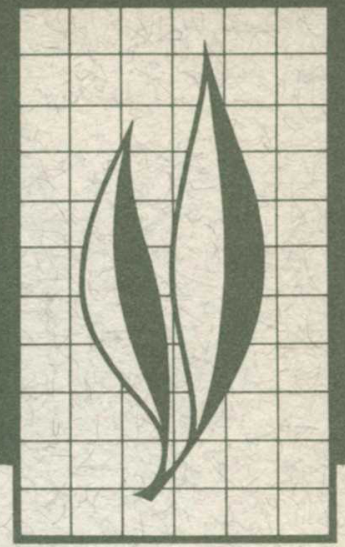

\title{
Spatial Variability of Field-Measured Soil-Water Properties
}

D. R. Nielsen, J. W. Biggar, and K. T. Erh

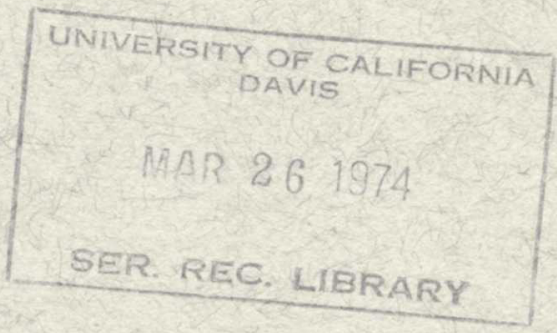

HILGA4 42 (7) 215-260 (1973) 


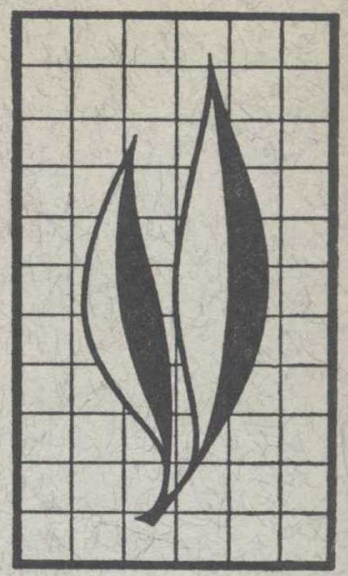

Infiltration and redistribution of water following an irrigation was studied, and the work was replicated at 20 locations on a 150hectare plot of land. Hydraulic conductivity was measured as a function of soil-water content at $30.5 \mathrm{~cm}$ depth intervals to a depth of 182.9 in twenty 6.5-meter-square plots randomly established over a 150-hectare field. Tensiometers installed at 30.5, 61.0, 91.4, $121.9,152.4$, and $182.9 \mathrm{~cm}$ were used to measure hydraulic gradients. Soil-water contents were ascertained from soil-water characteristics obtained from six soil cores taken from each of the above depths for each plot. Variations in soil-water content were found to be normally distributed with depth and with horizontal distance throughout the field, while values of the hydraulic conductivity were found to be log-normally distributed. The correlation between hydraulic conductivity during steady-state infiltration and the clay fraction was significant at the 1 per cent level. Several equations for predicting water movement and retention under field conditions are examined.

\section{THE AUTHORS:}

Donald R. Nielsen and James W. Biggar are Professors of Water Science, Department of Water Science and Engineering, Davis; Koon T. Erh is Postgraduate Research Water Scientist, Department of Water Science and Engineering, Davis. 


\section{Spatial Variability of Field-Measured Soil-Water Properties ${ }^{1}$}

\section{INTRODUCTION}

WATER IS THE MEDIUM in which biological and chemical transformations of nitrogen occur and in which nitrogen in its different forms moves and is transported in the soil profile, either to plant roots or out of the profile into drains and eventually into the groundwater. To predict nitrogen behavior in soil, therefore, one must first be able to predict water retention and movement.

Water and nitrogen movement studies are made more complex by characteristics common to most field soils: their variability and heterogeneity. These characteristics complicate analytic expressions developed to describe and predict the movement of nitrogen and water under a variety of conditions involving extensive land masses. With the development of these expressions, it is important to assess to some degree the confidence that can be attached to the predictions made by the models. It is also essential to recognize that useful predictions may be attained, even when some degree of accuracy has to be forfeited because the amount of input data is sparse and the cost of collecting data is prohibitive. Therefore, analytic expressions that require simple solutions involving a minimum of field measurements of selected soil-water variables are desirable.

The experiment had three objectives. The foremost was to evaluate the type and magnitude of spatial variation found over a field considered generally uniform relative to most cultural practices. This information is of value when assessing and evaluating the properties of an entire field on the basis of limited data from only a few locations. The second objective was to evaluate the suitability of various soil-water equations for predicting water movement under field conditions. These equations vary greatly in their assumptions and, therefore, in their complexity. Our final objective was to determine if any useful relationship could be developed between laboratory measurements of particle-size analysis, bulk density, and soil-water characteristic curves, and to study the movement of water under field conditions.

Only a few field studies have been conducted to examine the influence of spatial variation on water movement, whereas considerable effort has been made to evaluate the variation expected in soils (Beckett and Webster, 1971) and their physical characteristics (Andrew and Sterms, 1963; Jacob and Klute, 1965; Mason et al., 1957; McIntyre and Tanner, 1959; and Shaw et al., 1959), as well as their chemical characteristics (Hammond et al., 1958). In order to evaluate the true variation in water movement that exists from place to place in any area, an unmanageably large number of

\footnotetext{
${ }^{1}$ Submitted for publication January 30, 1973.
} 
samples would be required. To keep measurements within a manageable size, 20 locations within the 150 hectares were randomly selected. The same experiment was conducted on each plot, and measurements were made of particle-size distribution, bulk density, soil-water characteristic curves, water storage, water flux, hydraulic conduc- tivity, and soil-water diffusivity at depths of $30.5,61.0,91.4,121.9,152.4$, and $182.9 \mathrm{~cm}$ at each location. Subsequently, the measured values were used to evaluate simplified methods for determining hydraulic conductivity and flux and to estimate variability in the 150-hectare field when treated as an homogeneous unit.

\section{FIELD SITE AND EXPERIMENTAL DESIGN}

\section{Description of experimental area}

The field experiment was conducted at the West Side Field Station of the University of California, located in Fresno County 40 miles southwest of Fresno. Fresno County is in the southernmost quarter of the central valley of California, which is an elongated trough paralleling the eastern and western boundaries of the state. The valley is 500 miles long in . a northsouth direction and averages about 40 miles in width. The valley is surrounded by mountains except for the outlet into San Francisco Bay through which the valley rivers drain.

The climate at the West Side Field Station has two seasons of contrasting precipitation, temperature, and humidity. During the dry season (April through October) rainfall is lacking for long periods. Average temperatures are high during the cloudless midsummer days, with maximum values ranging between $38^{\circ}$ and $43^{\circ} \mathrm{C}$ for a week or two at a time. The nights are generally cool and pleasant. During the rainy season (November through March) precipitation occurs as gentle rains and usually varies from 12 to $25 \mathrm{~cm}$ annually. The measured rainfall at the station for 1966-1971 was $10.5,15.6,14.9,33.6,17.4$ and 9.3 $\mathrm{cm}$ per year. The growing season averages 251 days per year.

High-value crops in the area are dependent upon the availability of irrigation water. The recent development of the California Water Plan has introduced high-quality irrigation water to the area, and the cropping pattern is changing from one of primarily barley, flax, cotton, and alfalfa to a more diversified cropping program including vegetables and tree crops. Previous to development of the California Water Plan, irrigation water was derived from either a perched water table approximately 30 feet below the ground surface and of poorquality water, or from a water table located 700 to 800 feet below the soil surface and of slightly higher water quality.

The West Side Field Station is on an alluvial fan of Panoche soil series. Panoche soils have uniform profiles but a wide range of textures. They are light brownish, grey, calcareous, friable, and permeable throughout. The source of this soil is principally the softly consolidated calcareous and gypsiferous sandstone and shale on the eastern slope of the Coast Range. They are generally free of alkali or only slightly affected.

\section{Experimental design}

In order to determine variations in rates of infiltration and redistribution in the Panoche soil, twenty 6.5-metersquare plots were randomly established over a 150-hectare site at the West Side Field Station (fig. 1). Mercury tensiometers were placed in duplicate in each plot at depths of 30.5, 61.0, 


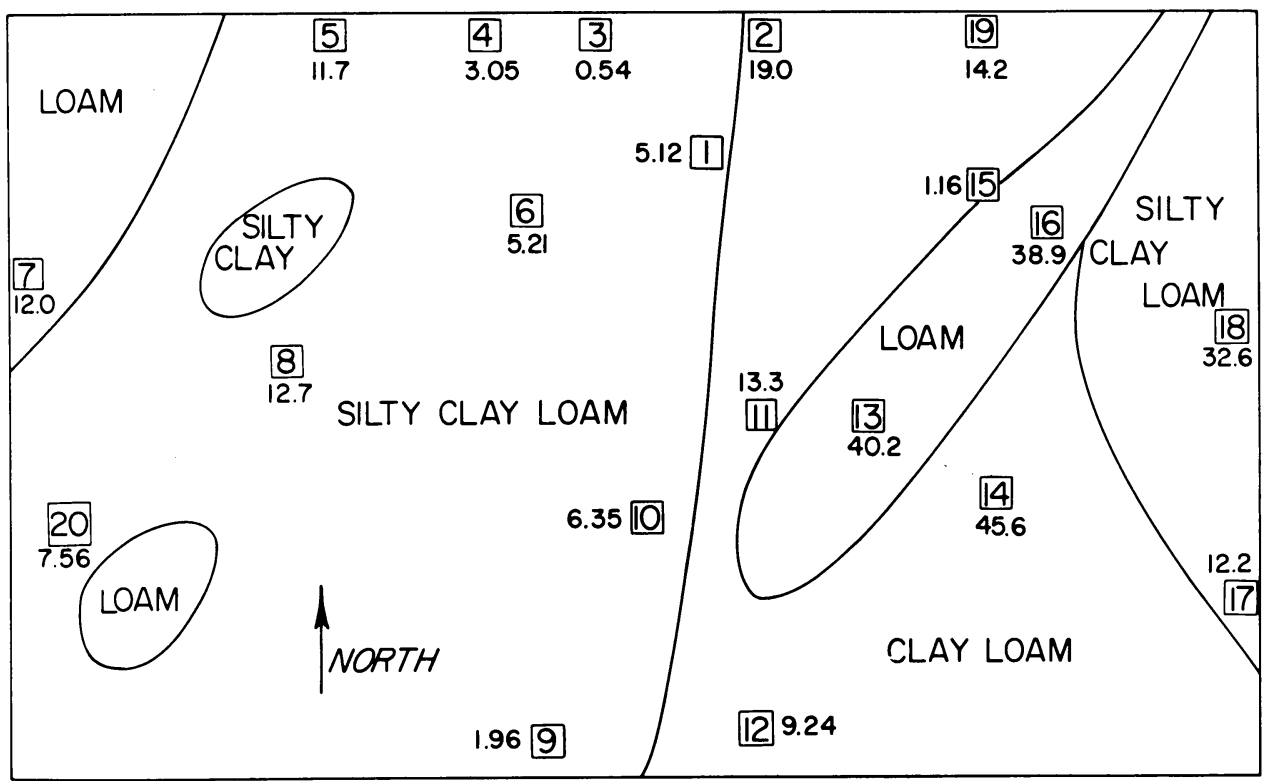

Fig. 1. Diagram of the field site showing locations of the plots ( 1 through 20 ). The number by each plot indicates the measured value of the steady-state infiltration rate ( $\mathrm{cm} \mathrm{day}^{-1}$ ). Textures at the soil surface of the Panoche soil are also indicated.

$91.4,121.9,152.4$, and $182.9 \mathrm{~cm}$ to follow soil-water pressure changes during redistribution and initial wetting. Additional tensiometers were installed in five plots at $300 \mathrm{~cm}$ with suction probes at 300,450 , and $600 \mathrm{~cm}$.

The plots were leveled and enclosed by planking installed in narrow trenches to a depth of $20 \mathrm{~cm}$, and the soil was thoroughly compacted around the planking to prevent leakage. The enclosure provided $10.5 \mathrm{~cm}$ of freeboard in which water could be ponded to any desired depth.

The tensiometers located in the center of the plot (in an area 2 meters square) consisted of a plastic barrel, a porous cup, a neoprene stopper, and a small-diameter water-filled nylon tube which connected the water in the plastic barrel to a vertical glass tube 1 meter long, which dipped into a mercury reservoir (fig. 2). Adjacent to each glass rod was a meter stick graduated in $\mathrm{mm}$ to permit convenient readings of soil-water pressure. Measured values of the mercury length $x(\mathrm{~cm})$, together with those of distance $y(\mathrm{~cm})$ and soil depth $z(\mathrm{~cm})$, were used in the following formula to calculate the soil-water pressure head $h(\mathrm{~cm})$

$$
h=-(12.55 x-y-z)
$$

Appendix A (see footnote for availability of appendices mentioned herein $)^{2}$ contains details of a Wang computer program used to calculate values of $h$ from tensiometer readings $x, y$, and $z$.

\footnotetext{
${ }^{3}$ Positive film strips of these appendices for use in a microfilm reader are on deposit in the Agricultural Reference Service, University of California Library, Berkeley, and in the Library of The U. S. Department of Agriculture, Washington, D.C. These are identified in the card catalog as follows:

Nielsen, D. R. et al., Spatial variability of field-measured soil-water properties. Microfilm supplement, 511 pages. Hilgardia 42 (7) November, 1973.

Copies of the entire microfilm supplement may be purchased from the Library Photographic Services, University of California, Berkeley 94720. Specify LPS Misc. Microfilm No. 79.
} 
Infiltration was initiated by ponding well water on each plot until steady-state flow was established in the profile at all depths to $182.9 \mathrm{~cm}$ (i.e., until mercury levels in the tensiometers remained constant). The time required for steady-state conditions was about 1 week. The rate of subsidence of the ponded water, or the rate at which water was applied to each plot, defined the steady-state infiltration rate. Chemical analysis revealed the following cations and anions present (meq per liter) in the well water: sodium, 9.6; calcium, 2.7; magnesium, 2.5; potassium, 0.1 ; bicarbonate, 1.4 ; chloride, 3.2 ; sulfate, 9.8 ; and nitrate, 0.01 . The surface of the plot was covered with a 7-meter square sheet of 6-mil black plastic to prevent evaporation when infiltration was complete. The plastic was covered with a thin layer of soil to hold it in place and to prevent extreme temperature fluctuations caused by its black color. Tensiometer readings were taken hourly for the first 24 hours following infiltration and then less frequently as time passed. After 3 or 4 days following infiltration, readings were taken once a day at 8 a.m. In certain plots, tensiometer measurements were continued in excess of 100 days.

Three 7.6 by $7.6-\mathrm{cm}$ soil cores were removed at each $30.48-\mathrm{cm}$ depth on two opposite sides of each plot from a pit 200-cm deep dug by hand or by back hoe. Additionally, soil samples were taken from the face of each pit at 15.24-cm intervals to a depth of 182.9 $\mathrm{cm}$. The samples were placed in plastic bags and taken to a glasshouse where they were dried, mixed, and sieved prior to laboratory analysis.

For obtaining core samples, soil was carefully cleared from the face of each

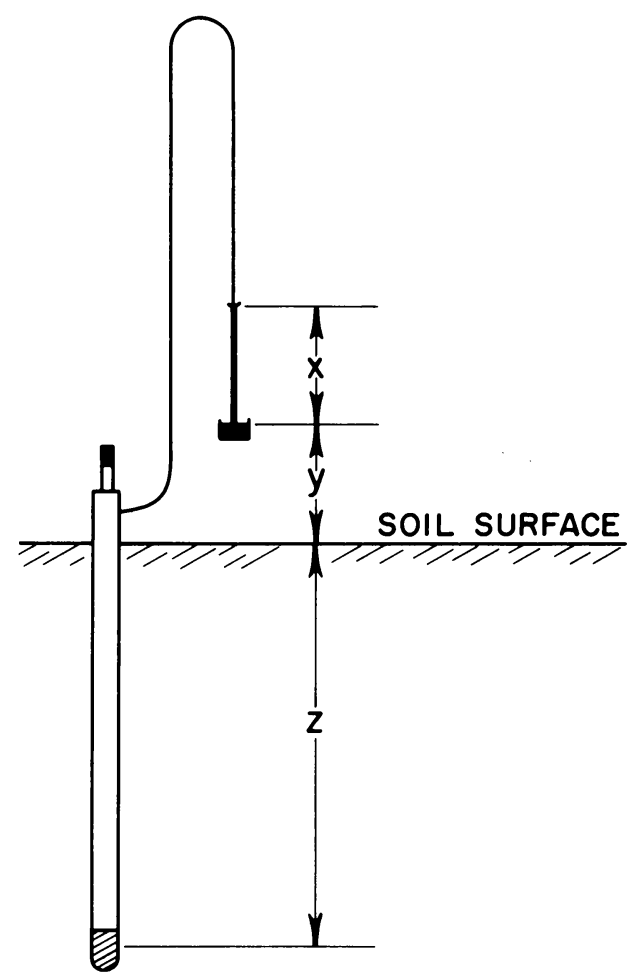

Fig. 2. Schematic diagram of tensiometer installation with porous cup at depth $z$, level of mercury reservoir $y$, and mercury length $x$.

pit to provide a horizontal plane into which 7.6 by $7.6-\mathrm{cm}$ core cylinders could be driven and removed with an Uhland sampler. Inasmuch as three cores were taken at each 30.48-cm depth (to 182.9 $\mathrm{cm}$ ) from each pit, a total of six cores at each depth per plot was sampled. The cores were encased in wax-coated cartons, sealed, and stored in a refrigerator prior to laboratory analysis. All leveling and depth measurements were made with a surveyor's level to that all depth measurements would be equivalent and accurate. Soil-water characteristic curves and soil-bulk density values were determined in the laboratory, using the soil cores. 


\section{LABORATORY METHODOLOGY}

\section{Particle size distribution and soil bulk density}

The hydrometer method (Day, 1965) was used for determining the particlesize distribution of soil samples taken from the face of the pits on each side of every plot. These samples, which were removed at $15.24-\mathrm{cm}$ intervals from 40 pits, collectively totaled 480 in number over the field.

The oven-dried weight of the soil cores obtained when the soil-water characteristic curve was experimentally determined was also used to calculate soil-bulk density. The value of the average soil-bulk density for the entire field stemmed from 720 soil cores, the sum of 120 cores at each of the six depths.

\section{Soil-water characteristics curve}

The curve describing the amount of water retained by a soil at different soil-water pressures is defined as the soil-water characteristic curve. After each of the 720 soil cores previously sealed in wax-coated cartons in the field was removed from the carton, both ends of the core were carefully trimmed. Each core sample still containing its field soil-water content was placed in a covered glass funnel fitted with fritted-glass plates and connected to a supply of $0.01 \underline{\mathrm{N}} \mathrm{CaSO}_{4}$ to saturate the soil. When the soil was thoroughly saturated, excess water was removed and the soil-water pressure was controlled either by a hanging water column or by air pressure. The volume of water extracted was measured and recorded for each incremental decrease in pressure. Care was taken to minimize evaporation losses. At the end of extraction, cores were dried to constant weight at $105^{\circ} \mathrm{C}$. The soil-water characteristic curves for the six cores (three cores from each of two pits) taken at each depth were averaged to yield a single curve. For each plot the resulting average soil-water characteristic curve for each depth was used to relate tensiometer readings obtained in the field to soil-water content. The reliability of ascertaining soilwater content from tensiometric data in the field has been examined and discussed by LaRue et al. (1968).

\section{FIELD METHODOLOGY AND PHYSICAL ANALYSIS}

\section{Storage}

At any given time the amount of water stored at each depth was obtained from tensiometer readings. For each tensiometer reading, the water content was obtained from the soil-water characteristic curve for the particular plot and soil depth. Inasmuch as the water content from the soil surface to a depth of $30.5 \mathrm{~cm}$ was assumed to be identical to that at $30.5 \mathrm{~cm}$, the water stored in the 0 to $30.5-\mathrm{cm}$ depth was 30.5 times the water content at the $30.5-\mathrm{cm}$ depth. The water stored from the soil surface to any depth $L$ was the water stored from 0 to $30.5 \mathrm{~cm}$ plus that stored be- tween 30.5 and $L \mathrm{~cm}$. The latter amount for any given time was obtained by fitting the water content data for 30.5 , $61.0,91.4,121.9,152.4$, and $182.9 \mathrm{~cm}$ using a cubic spline function (Erh, 1972 ) with the aid of the computer program given in Appendix B. This function $\theta\left(z, t_{i}\right)$ was integrated from $z$ equal to 30.5 to $L$ to obtain the water stored in the profile at different times $\left(t_{i}\right)$ following the cessation of infiltration. Hence, the amount of water stored $S_{L}$ $(\mathrm{cm})$ at time $t_{i}$ was equal to

$$
S_{L}\left(t_{i}\right)=30.5 \theta\left(30.5, t_{i}\right)+\int_{30.5}^{L} \theta\left(z, t_{i}\right) d z .
$$




\section{Soil-water flux}

Soil-water flux is the quantity of water leaving the profile per unit time across a specific depth. The value of the flux across depth $L$ was calculated for each plot from the time rate of change of the amount of water stored in the profile from the soil surface to the depth $L$. Its value (also calculated with the computer programs given in Appendix B) is $d S_{L}(t) / d t$, which is the derivative of the above equation for $S_{L}$. For steady-state infiltration conditions which prevailed initially for all plots, the soil-water flux was assumed identical for all soil depths and equal to the measured steady-state infiltration rate.

\section{Hydraulic conductivity}

A measure of the rate that a particular soil will conduct water at a given water content is known as its hydraulic conductivity. It is the proportionality factor in the Darey flow equation

$$
J=-K(\theta) \nabla H
$$

where $J$ is the soil-water flux $\left(\mathrm{cm}^{3} \mathrm{~cm}^{-2}\right.$ day $\left.^{-1}\right), K(\theta)$ the hydraulic conductivity $\left(\mathrm{cm} \mathrm{day}^{-1}\right)$, and $\nabla \mathrm{H}$ the hydraulic head gradient. Here, $H$ the hydraulic head $(\mathrm{cm})$ is the sum of the soil-water pressure head $h(\mathrm{~cm})$ and the gravitational head or vertical distance $z(\mathrm{~cm})$. The soil-water content is given as $\theta\left(\mathrm{cm}^{3}\right.$ $\left.\mathrm{cm}^{-3}\right)$.

Values of hydraulic conductivity are sensitive to small changes in water content. Characteristically, hydraulic conductivity value decreases in order of magnitude for only a small decrease in water content. It is not unusual for hydraulic conductivity values to range over a factor of $10^{5}$ for water contents measured in the field.

Numerous experimental methods have been developed to measure the hydraulic conductivity. These methods include steady-state columns (Klute, 1965) and field studies (Richards et al., 1956; Nielsen et al., 1961; Rose et al., 1965; LaRue et al., 1968; and Davidson et al., 1969).

Combining equation [1] with the equation of continuity

$$
\frac{\partial \theta}{\partial t}=-\frac{\partial J}{\partial z}
$$

gives the following basic differential equation for soil-water flow in the vertical direction

$$
\frac{\partial \theta}{\partial t}=\frac{\partial}{\partial z}\left(K(\theta) \frac{\partial H}{\partial z}\right)
$$

where $t$ is time in days.

In order to obtain the value of $K$ at soil depth $L$, we integrate equation [2] with respect to $z$ from the soil surface $(z=0)$ to the desired soil depth $(z=-\mathrm{L})$

$$
\int_{0}^{-L} \frac{\partial \theta}{\partial t} d z=\left.K \frac{\partial H}{\partial z}\right|_{z=-L}-\left.K \frac{\partial H}{\partial z}\right|_{z=0}
$$

Because there is no flow across the plastic-covered soil surface, the second term on the right-hand side of equation [3] is zero. Substituting $(h+z)$ for $H$, equation [3] becomes

$$
\int_{0}^{-L} \frac{\partial \theta}{\partial t} d z=K\left[\frac{\partial h}{\partial z}+1\right]_{z=-L}
$$

In order to use discrete experimental values in equation [4] we define $\Delta \theta=$ $\left(\theta_{i+1}-\theta_{i}\right)$ and $\Delta t=\left(t_{i+1}-t_{i}\right)$ where the subscripts represent two different time values. For example, if $i=1, \Delta \theta$ is the water content on day two minus the water content on day one. This designation changes equation [4] to

$$
\begin{gathered}
\frac{1}{t_{i+1}-t_{i}} \int_{o}^{-L}\left[\theta_{i+1}(z)-\theta_{i}(z)\right] d z= \\
K(\bar{\theta})\left(\frac{\partial \bar{h}}{\partial z}+1\right)
\end{gathered}
$$


where the bar above $\theta$ and $h$ represents average values over the time period $\triangle t$. Rearranging terms in equation [5], the value of the hydraulic conductivity is calculated from

$$
K(\bar{\theta})=\frac{1}{\left(t_{i+1}-t_{i}\right)\left(\frac{\partial \bar{h}}{\partial z}+1\right)} \int_{0}^{-L}\left[\theta_{i+1}(z)-\theta_{i}(z)\right] d z
$$

where

$$
\bar{\theta}=\frac{1}{2}\left[\theta_{i+1}(-L)+\theta_{i}(-L)\right]
$$

and

$$
\frac{\partial \bar{h}}{\partial z}=\frac{1}{2}\left[\frac{\partial h_{i+1}}{\partial z}+\frac{\partial h_{i}}{\partial z}\right]
$$

A smooth curve was drawn through values of $h(z)$ using the cubic spline function in order to evaluate the slope $\partial h / \partial z$ mathematically.

Values of $K(\theta)$ were obtained from equation [6] using the program given in Appendix B.

\section{Soil-water diffusivity}

Soil-water diffusivity defined by Childs and Collis-George (1950) is somewhat difficult to visualize physically, but mathematically it is simply the product of the hydraulic conductivity at a given water content and the reciprocal of the slope of the soil-water characteristic curve at that same water content. Hence,

$$
D(\theta)=K(\theta) \frac{d h}{d \theta}
$$

Values of $D(\theta)$ are not as sensitive to changes in water content as values of the hydraulic conductivity. Maximum values are about $10^{4}$ while minimum values are about $10^{2} \mathrm{~cm}^{2}$ day $^{-1}$ for water contents manifested in the Panoche soil.

A number of experimental techniques have been developed to measure soilwater diffusivity. These include: the outflow method (Gardner, 1956), which is based on measurement of the volume of water outflow as a function of time from a sample in a laboratory pressure cell; and an infiltration method utilizing horizontal soil columns (Bruce and Klute, 1956). In our study, diffusivity was obtained by multiplying values of $K(\theta)$ measured by the method described above times values of $d h / d \theta$ obtained from the soil-water characteristic curve. These values were introduced into equation [7], using the program given in Appendix B.

\section{SIMPLIFIED, APPROXIMATE PHYSICAL ANALYSIS}

Although analytic mathematical expressions based upon equation [2] for soil-water movement and retention are available, measurements of soil-water properties over the 150 -hectare field reveal clearly that the soil is not strictly homogeneous. Because of soil variations over this (including those associated with soil depth) approximate analyses may suffice to predict water movement within the limitations of the soil itself, and to measure soil-water properties applicable to the entire field. The following approximate methods were examined for their potential in yielding results acceptable within the limits of the soil variability. If found acceptable, they offer a relatively simple means of 
characterizing soil-water properties on a field scale without the necessity of collecting huge quantities of data to be processed by costly, time-consuming analytical methods. Values derived by each approximate method were compared with those stemming from measured values of those calculated analytically.

\section{Hydraulic conductivity:}

\section{a simple field method}

Inasmuch as the product of the hydraulic conductivity and the hydraulic gradient give the soil-water flux, hydraulic conductivity is usually obtained by measuring these latter two terms. For steady-state infiltration, the soilwater flux is measured at the soil surface and calculations of $K$ are made easily. For transient conditions of a draining profile without evaporation, the rate of change in soil-water content in the profile can be used as a basis for calculating $K$, as was done in equation [6].

Values of $\partial \theta / \partial t$ as a function of $z$ could be measured gravimetrically, by neutron moderation, gamma-radiation attenuation, or by any other practical means. Thus, as water content in the profile decreases owing to drainage, the value of $K$ at different water contents can be readily calculated if $\partial h / \partial z$ is measured directly or estimated. Equation [4] may be simplified by approximating the integral with the product of the soil depth $L$ and the rate of change of average soil-water content in the profile $\bar{\theta}$ (Black et al., 1969). Equation [4] can be further simplified by assuming that the hydraulic gradient $\partial H / \partial z$ is equal to unity, or that $\partial h / \partial z$ is zero. Hence,

$$
L \frac{d \bar{\theta}}{d t}=-\left.K\right|_{z=-L}
$$

Values of $K$ calculated from equation [8] were compared with those ascertained, using equation [6].

\section{Soil-water diffusivity: field method}

Inasmuch as soil-water diffusivity is simply the product of hydraulic conductivity and the reciprocal slope of the soil-water characteristic, equation [4] can be modified to approximate the diffusivity. If equation [4] is simplified by approximating the integral with the product of the soil depth $L$ and the rate of change of the average soil-water content in the profile $\bar{\theta}$ (with the value of the hydraulic gradient retained) it becomes

$$
L \frac{\partial \bar{\theta}}{\partial t}=-\left.K \frac{\partial H}{\partial z}\right|_{z=-L}
$$

Assuming that an average soil-water characteristic curve holds for the entire profile $(d \bar{\theta} / d h)(\partial h / \partial t)$ can be substituted for $\partial \bar{\theta} / \partial t$ and using the relation $D=K d h / d \theta$, equation [9] becomes

$$
L \frac{\partial h}{\partial t}=-\left.D \frac{\partial H}{\partial z}\right|_{z=-L}
$$

Hence, the value of $D$ may be calculated for each depth $L$ using only tensiometers. The value of $\partial h / \partial t$ is merely the time rate of change of the soil-water pressure head $h$ obtained from tensiometer readings for depth $L$. The value of $\partial H / \partial z$ can be estimated using a second tensiometer above or below depth $L$.

Equation [10] can be further simplified by assuming that the hydraulic gradient is unity and hence,

$$
L \frac{d h}{d t}=-\left.D\right|_{z=-L}
$$

With equation [11], the diffusivity can be determined by using a single tensiometer at a depth $\mathrm{L}$ to obtain the time rate of change of the soil-water pressure head and thereby calculate $D$.

Values of the soil-water diffusivity 
calculated from equations [10] and [11] were compared with those using equation [7]. Procedures outlined in Appendix B were used to calculate soil-water diffusivity values from each of the three equations.

\section{Hydraulic conductivity:}

\section{laboratory method}

A number of investigators have explored the possibility of predicting the hydraulic conductivity of a soil from its pore-size distribution being estimated from the soil-water characteristic curve. For example, Childs and Collis-George (1950), Marshall (1958),
Millington and Quirk (1959, 1960, 1961), and Kunze et al. (1968) have proposed such methods. Experience has shown that a matching factor, that is, a multiplier that forces the predicted curve to fit the experimental data at one point is required. This ploy means that at least one value of the hydraulic conductivity value from a field or laboratory measurement must be known. These methods have been shown to be reasonably effective in predicting experimentally measured values (Nielsen et al., 1960; Jackson et al., 1965; Sharma, 1966; Kunze et al., 1968).

The equation proposed by Childs and Collis-George is

$$
K=M\left(a^{2} \alpha^{2}+b^{2} \beta^{2}+c^{2} \gamma^{2}+\ldots+2 a^{2} \alpha \beta+2 a^{2} \alpha \gamma+\ldots+2 b^{2} \beta \gamma+\ldots\right)
$$

where $M$ is the matching factor, $a, b, c$, etc. are mean radii (inversely proportional to soil-water pressure) of the pore groups and $\alpha, \beta, \gamma$, etc. are porosity elements. The above series termi- nates at the largest water-filled pore size.

The equation used by Marshall, and by Millington and Quirk is:

$$
K=3600 \times 24 \frac{\gamma^{2}}{2 \rho^{2} g \eta} \frac{\theta^{p}}{n^{2}}\left(h_{1}^{-2}+3 h_{2}^{-2}+\ldots+(\alpha n-1) h_{n}^{-2}\right) \ldots
$$

and by Kunze et al. is

$$
K=3600 \times 24 \frac{\gamma^{2}}{\rho g \eta} \frac{\theta^{p}}{n^{2}}\left(h_{1}^{-2}+3 h_{2}^{-2}+\ldots+(\alpha n-1) h_{n}^{-2}\right) \ldots
$$

where $\gamma$ is the surface tension of water, $\rho$ the density of water, $g$ the acceleration due to gravity, and $\eta$ the viscosity of water. For Marshall's method $p$ equals 2 and $n$ is the number of pore classes up to the water content of interest. In other words, $n$ is different for calculating $K$ at different water content. For Millington and Quirk's method, $p$ equals $4 / 3$ and $n$ is the total number of pore classes. For the method of Kunze et al. $p$ equals 1 and $n$ is the total number of pore classes.

Soil-water characteristic curves for each depth of each plot were used to calculate values of hydraulic conductivity as a function of soil-water con- tent. Measured and calculated values of hydraulic conductivity were matched at water-content values that prevailed during steady-state infiltration conditions. The computer program used to calculate the theoretical values of $K$ from equations [12], [13], and [14] is given in Appendix C. The total number of pore classes used in this program were $4,8,16,32$, and 64 .

\section{Estimated soil-water flux}

The rate of deep drainage after infiltration stops has been examined by a number of investigators (Miller and Aarstad, 1972; Robins et al., 1954; Ogata and Richards, 1957; Wilcox, 
1960). Each noted that drainage occurs for many days following an irrigation. This downward movement of water through the profile has numerous implications relating to the leaching and redistribution of soluble salts and fertilizers.

Let us assume that hydraulic conductivity is an exponential function of soil-water content, such that

$$
K(\theta)=K_{o} \exp \left[\alpha\left(\theta-\theta_{o}\right)\right]
$$

where $K_{o}$ and $\theta_{o}$ are values of $K$ and $\theta$ corresponding to steady-state infiltration conditions. The value of the constant $\alpha$ is chosen to provide the best fit line for known values of $K$ and $\theta$. Substituting equation [15] into equation [9], assuming $\theta$ to be invariant and equal to $\bar{\theta}$ to depth $L$, and inte- grating from $O$ to $t$ and from $\theta_{o}$ to $\theta$, yields

$\theta=\theta_{o}-\alpha^{-1} \ln \left(1+\alpha K_{o} t L^{-1}\right)$

Differentiating equation [16] with respect to $t$ and multiplying by the depth $L$ yields the magnitude of the soil-water flux $J_{L}$ at depth $L$

$$
J_{L}=K_{o}\left(1+\alpha K_{o} t L^{-1}\right)^{-1} .
$$

The ability of equation [17] to describe the soil-water flux depends upon how closely the assumption that a unit hydraulic gradient exists is met and how well equation [15] describes the values of $K(\theta)$. Values of $J_{L}$ calculated from equation [17] are to be compared with values measured at each soil depth.

\section{DETAILED ANALYSIS OF SOIL PROFILE}

Most analyses of soil-water redistribution for cases involving non-homogeneous or layered soil profiles have attempted to describe the actual condition as closely as possible using soilwater properties appropriate for each soil layer (doing so would minimize the gross assumptions we have made in the previous section). Such analyses are necessarily more time-consuming, but they provide some advantages in accuracy that might not be obtained from less detailed but more rapid methods. Comparisons of analytic and approximate methods should indicate how soil variability may determine the futility of a detailed analysis and dictate the acceptance of a simpler analysis. In the following detailed analysis, equation [2] is used to describe the redistribution of water within the $\mathbf{1 8 2 . 9}$ cm profile using values of $K(\theta)$ and $h(\theta)$ measured for each 30.5 -cm depth.

Rewriting equation [2] by introducing $h(\theta)$ and by assuming that $K$ is a function of time and space, we have

$$
\left.\left.\frac{\partial \theta}{\partial h}\right|_{z} \frac{\partial h}{\partial t}\right|_{z}=\left[\left.\frac{\partial K}{\partial z}\right|_{h}+\left.\left.\frac{\partial K}{\partial h}\right|_{z} \frac{\partial h}{\partial z}\right|_{t}\right]\left(\left.\frac{\partial h}{\partial z}\right|_{t}-1\right)+\left.K \frac{\partial^{2} h}{\partial z^{2}}\right|_{t}
$$

If no water evaporates at the soil surface as water redistributes within the profile, the following initial and boundary conditions are applicable:

$$
\begin{array}{rlrl}
h & =h_{e}(z) & t=0 & z \geq 0 \\
\left.\frac{\partial h}{\partial z}\right|_{t}=0 & z=0 & t=0 \\
\left.\frac{\partial h}{\partial z}\right|_{t}=0 & z=L & t \geq 0
\end{array}
$$


In general, difficulty has been encountered in the theoretical analysis with respect to the boundary condition that exists at the lower boundary in unsaturated flow of water during redistribution. To bypass the difficulty, Rubin (1967) and Wang and Lakshminarayana (1968) assumed a semiinfinite medium in which the water content approaches a constant value as $z \rightarrow \infty$. Numerically, this approach is unrealistic and time-consuming.

It was noted some time ago that when water redistributes within a field soil, the hydraulic gradient approaches unity at a given depth (Richards et $a l ., 1956$; Nielsen et al., 1964). Adopting this behavior with additional simplifications, Davidson et al. (1969) had reasonable success in prediction soil-water flux at various depths for three soils. Equation [21] assumes this behavior. Assuming

$$
\Phi(z)=h(z)-h_{e}(z),
$$

then equations [2], [3], [4], and [5] become

$$
\begin{gathered}
\left.\left.\frac{\partial \theta}{\partial \Phi}\right|_{z} \frac{\partial \Phi}{\partial t}\right|_{z}=\left[\left(\frac{\partial K}{\partial z}\right]_{\Phi}+\left.\frac{\partial K}{\partial \Phi}\right|_{z}\left(\left.\frac{\partial \Phi}{\partial z}\right|_{t}+\frac{2 h_{e}}{\partial z}\right)\right]\left(\left.\frac{\partial \Phi}{\partial z}\right|_{t}+\frac{\partial h_{e}}{\partial z}-1\right)-K\left(\left.\frac{\partial^{2} \Phi}{\partial z^{2}}\right|_{t}+\frac{\partial^{2} h_{e}}{\partial z^{2}}\right) \\
\Phi=0 \quad t=0 \\
\left.\frac{\partial \Phi}{\partial z}\right|_{t}=0 \quad z=0 \\
\left.\frac{\partial \Phi}{\partial z}\right|_{t}=0 \\
z=L
\end{gathered}
$$

An explicit-difference scheme was set up to solve the partial differential equation [22] subject to equations
[23], [24], and [25]. Equation [22] is discretized into the following equation:

$$
\begin{gathered}
\frac{\Phi_{i, j+1}-\Phi_{i, j}}{\Delta t}=\left\{\left[A_{i, j}+\right.\right. \\
\left.B_{i, j}\left(\frac{\Phi_{i+1, j}-\Phi_{i, j}}{\Delta z}+C\right)\right]\left(\frac{\Phi_{i+1, j}-\Phi_{i, j}}{\Delta z}+C-1\right) \\
\left.-K_{i, j}\left(\frac{\Phi_{i+1, j}-2 \Phi_{i, j}+\Phi_{i-1, j}}{(\Delta z)^{2}}+D\right)\right\}_{E_{i, j}^{-1}}
\end{gathered}
$$

where

$$
\begin{aligned}
A_{i, j} & =\left.\frac{\partial K}{\partial z}\right|_{\Phi_{i, j}} \\
B_{i, j} & =\frac{\partial K}{\partial \Phi_{i, j}} \\
C & =\frac{\partial h_{e}}{\partial z} \\
D & =\frac{\partial^{2} h_{e}}{\partial z^{2}}
\end{aligned}
$$

$$
E_{i, j}=\frac{\partial \theta_{i, j}}{\partial \Phi_{i, j}}
$$

The functional relations between $K$ and $h, \theta$ and $h$, as well as the initial condition $h_{e}(z)$, were approximated by a spline function (Erh, 1972). The computer program for solving equation [26] is given in Appendix D. 
TABLE 1

PARTICLE-SIZE DISTRIBUTION OF PANOCHE CLAY LOAM MEASURED AT 40 LOCATIONS IN THE 150-HECTARE FIELD

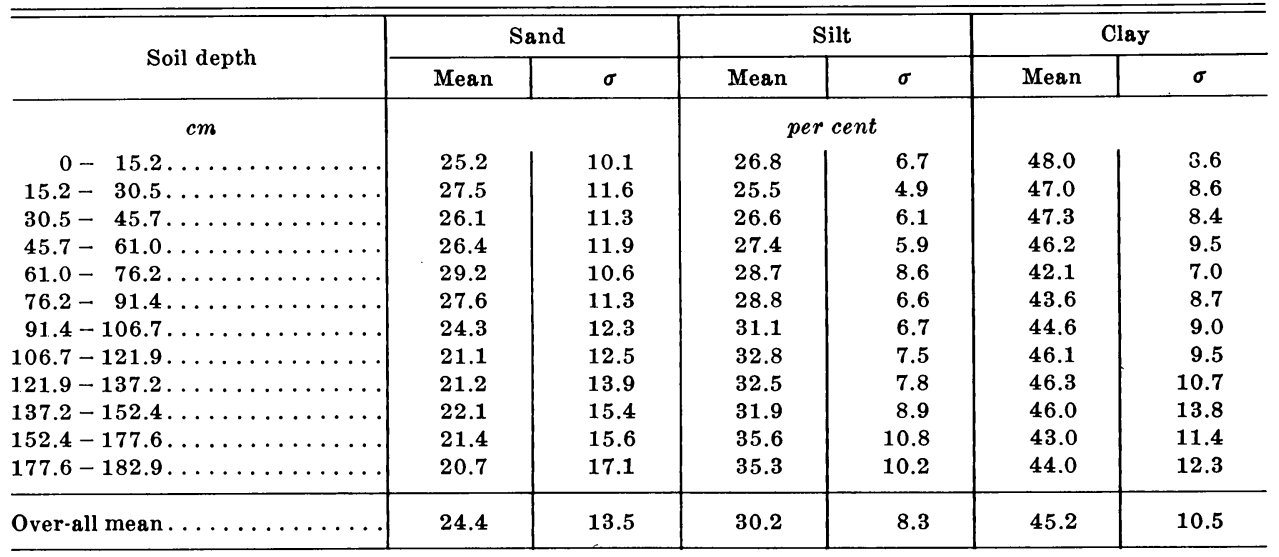

\section{RESULTS AND STATISTICAL ANALYSIS}

\section{Particle-size distribution}

Values of per cent sand, silt, and clay for each depth of each plot are given in Appendix $\mathbf{E}$. The average particle size distribution for each depth given in table 1 shows that the overall mean clay fraction of the entire field to a depth of $182.9 \mathrm{~cm}$ was 45.4 per cent with a standard deviation from the mean of 10.6 per cent. The percentages of sand, silt, and clay at the soil surface were $25.2,26.8$, and 48.0 , respectively. Percentages of sand and clay both decrease slightly with soil depth.

The normal frequency distribution function is

$$
f=\frac{1}{\sigma \sqrt{2 \pi}} \exp \left[-(x-m)^{2} / 2 \sigma^{2}\right]
$$

where $f$ is the frequency, $m$ the mean, $\sigma$ the standard deviation of the mean, and $x$ the random variable. Figure 3 depicts the clay fraction histogram and the normal frequency curve for 480 samples taken from the entire field. Frequency distributions for clay and sand were considered normal, while that for silt was too irregular to be described by equation [32].

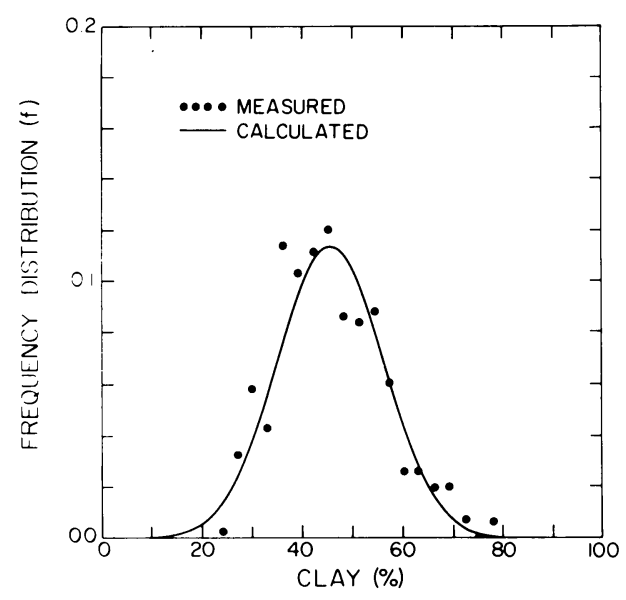

Fig. 3. Measured (480 samples) and calculated frequency distributions for clay fraction values throughout the entire field to a depth of $182.9 \mathrm{~cm}$. The curve is described by equation [32] for values of $m$ and $\sigma$ equal to 45.2 and 10.5 per cent, respectively.

\section{Soil-water characteristic}

Figure 4 gives average of 120 soilwater characteristic curves for each of the six depths. Data for each soil-water pressure applied to the soil cores are given in table 2. Each curve resembles the others inasmuch as they all have the same general shape and differ only by the magnitude of the soil-water 
TABLE 2

AVERAGE SOIL-WATER CHARACTERISTIC VALUES FOR 120 SOIL CORES FROM EACH SOIL DEPTH IN THE 150-HECTARE FIELD

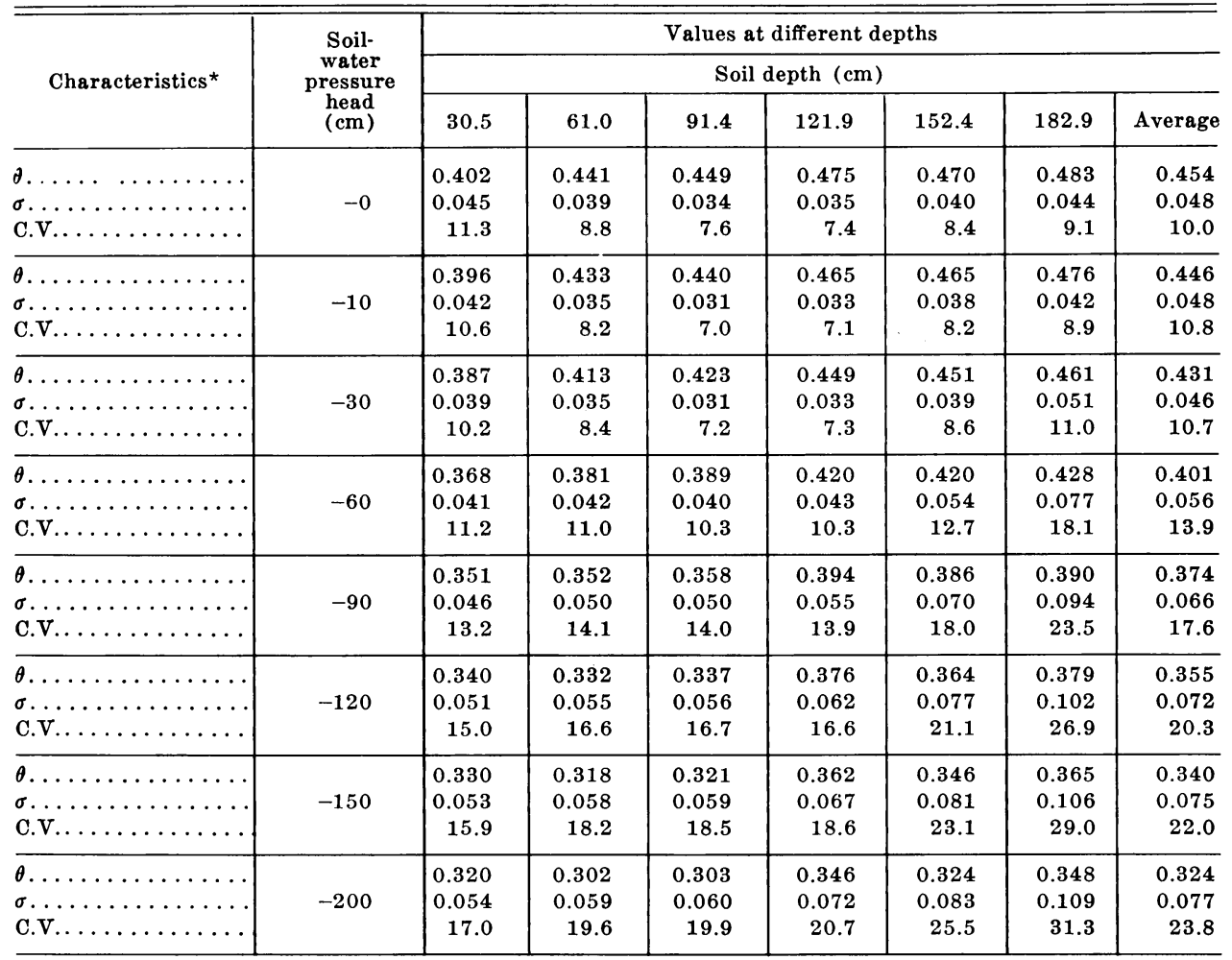

$* \theta$ is the mean water content $\left(\mathrm{cm}^{3} / \mathrm{cm}^{-3}\right) ; \sigma$ is the standard deviation of the mean; and C.V. is the coeffi. cient of variation (per cent).

content. Water contents at saturation range from 0.40 to $0.48 \mathrm{~cm}^{3} \mathrm{~cm}^{-3}$, while those at a pressure head of $-200 \mathrm{~cm}$ range between 0.30 and $0.35 \mathrm{~cm}^{3} \mathrm{~cm}^{-3}$. Unlike hand-packed sieved samples commonly used in laboratory studies of soil water, soil cores did not manifest a capillary fringe.

Values of the standard deviation of the mean represented by the shaded areas in figure 4 increase with decreasing soil-water pressures. The standard deviations at the smaller soil-water pressures also increase with soil depth corresponding to the greater variability of the clay fraction given prevously in table 1.

If the entire field to a depth of $182.9 \mathrm{~cm}$ is treated as a homogeneous mass of soil, the average of 720 soil- water characteristic curves for all six depths given in figure 5 shows that the soil-water content near water saturation can be estimated only within $\pm 0.05 \mathrm{~cm}^{3} \mathrm{~cm}^{-3}$, while that at a pressure head of $-200 \mathrm{~cm}$ has an uncertainty of $\pm 0.07 \mathrm{~cm}^{3} \mathrm{~cm}^{-3}$. Owing to the variability of the soil, and treating the soil profile as a composite of six soil layers, the soil-water content would be known no better than from \pm 0.03 to $\pm 0.11 \mathrm{~cm}^{3} \mathrm{~cm}^{-3}$ depending upon the soil-water pressure and soil depth. Soil-water characteristic data are summarized in Appendix F.

\section{Soil-bulk density}

The oven-dried weight of the soil cores revealed that soil is most compact in the top $30 \mathrm{~cm}$, with bulk density 


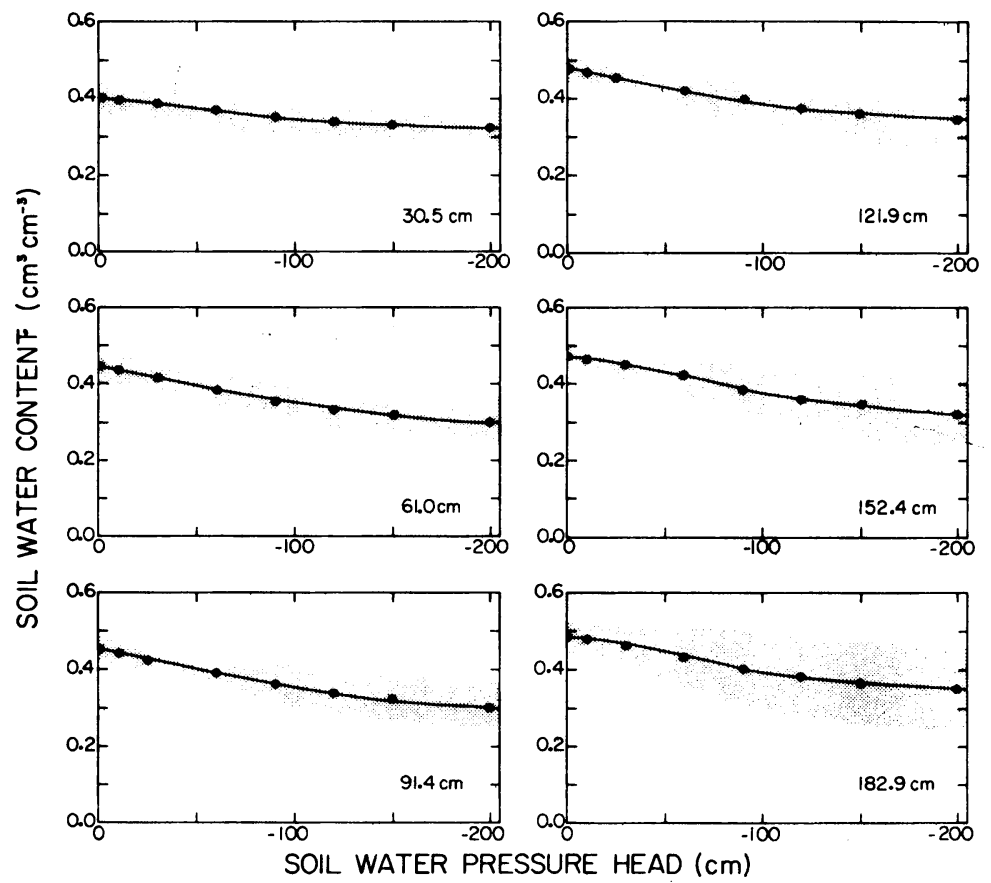

Fig. 4. Soil-water characteristic curves for the six soil depths. Each curve is the mean of the data obtained from 120 soil cores with the shaded area representing the standard deviations of the mean.

values decreasing gradually with depth. The average bulk density for each $30.48-\mathrm{cm}$ depth from 30.5 to 182.9 cm was 1.468, 1.366, 1.348, 1.312, 1.329, and $1.313 \mathrm{~g} \mathrm{~cm}^{-3}$. The corresponding values of the coefficient of variation (standard deviation for the mean divided by the mean and multiplied by 100) were $10.1,5.8,5.8,4.9,4.7$, and 5.9 per cent, respectively. The frequency distribution of the soil-bulk density for the entire field described by equation [32] is given in figure 6 together with measured values. The values are normally distributed. The data for each depth and plot are shown in Appendix G.

\section{Storage}

The term storage is used to describe the amount of water temporarily retained in the soil profile above a particular depth at any particular time. Figure 7 shows that the amount of water in the profile decreases monoton-

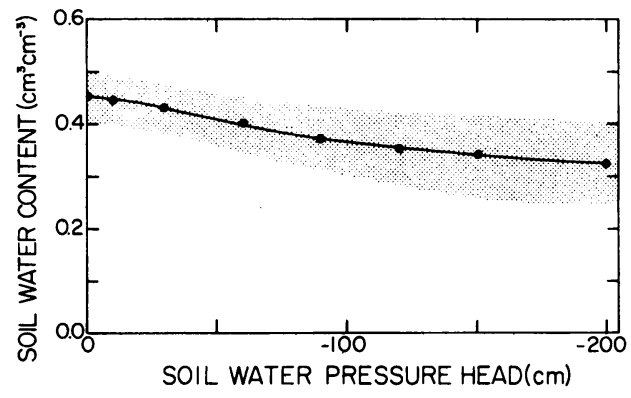

Fig. 5. Average soil-water characteristic curve for the 150-hectare field. Each point is the mean of the data from 720 soil cores, with the shaded area representing the standard deviations of the mean.

ically with time and that the amount of water stored is proportional to the depth of profile. Within the 182.9-cm profile, $76 \mathrm{~cm}$ of water initially stored at day zero had diminished to $61 \mathrm{~cm}$ following 20 days of drainage and redistribution. At the shallow depth of $30.5 \mathrm{~cm}$, a total of $12 \mathrm{~cm}$ of water had reduced to $10 \mathrm{~cm}$ for equivalent times. 


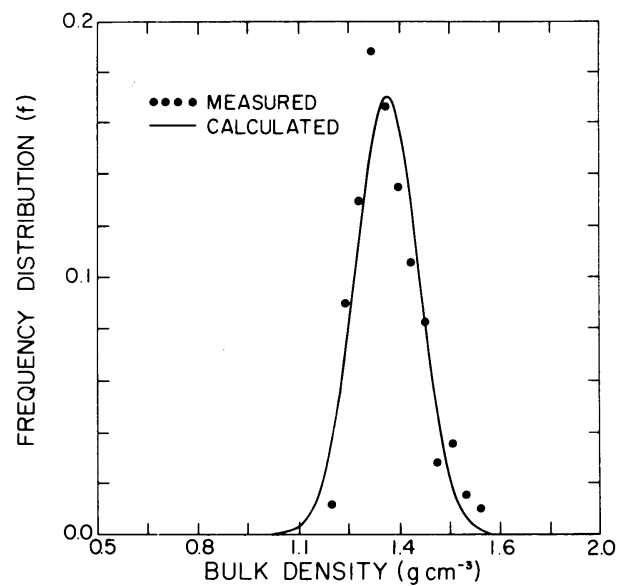

Fig. 6. Measured and calculated frequency distributions for soil-bulk density values throughout the entire field to a depth of 182.9 $\mathrm{cm}$. The curve is described by equation [32] for values of $m$ and $\sigma$ equal to 1.357 and 0.0947 $\mathrm{g} \mathrm{cm}^{-3}$, respectively.
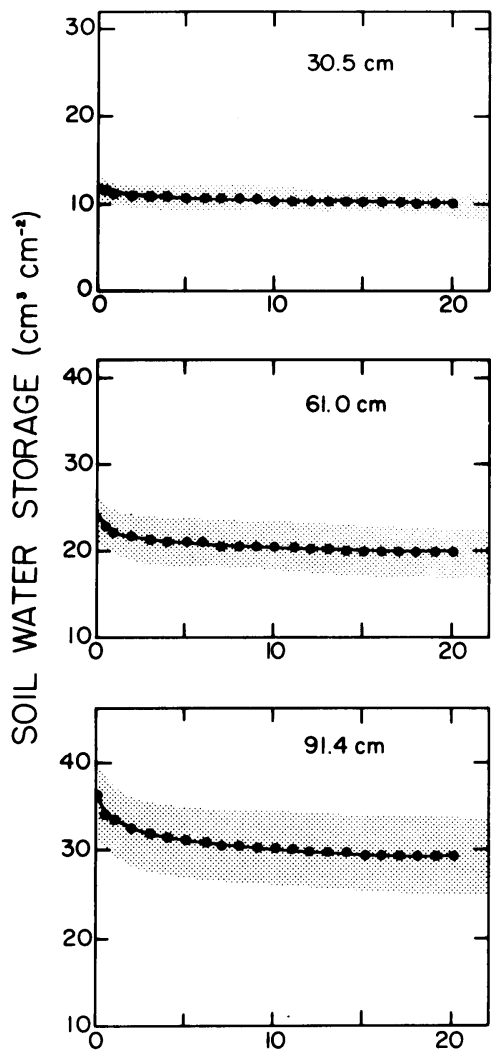

TIME (days)
The coefficient of variation was approximately 15 per cent at all depth and times. Values in figure 7 stem from measurements from all 20 plots, with the shaded areas delineating the standard deviation of the soil-water stored. Data for soil-water content and water storage for each depth and plot are given in Appendices $\mathrm{H}$ and $\mathrm{I}$, respectively.

\section{Soil-water flux}

Corresponding to the above changes in storage, the soil-water flux increases in general with depth and decreases with time following an irrigation. For example the flux at the 121.9-cm depth for the second day following infiltration is $1.24 \mathrm{~cm} \mathrm{day}^{-1}$ and is the amount of water $(\mathrm{cm})$ represented by the area be-
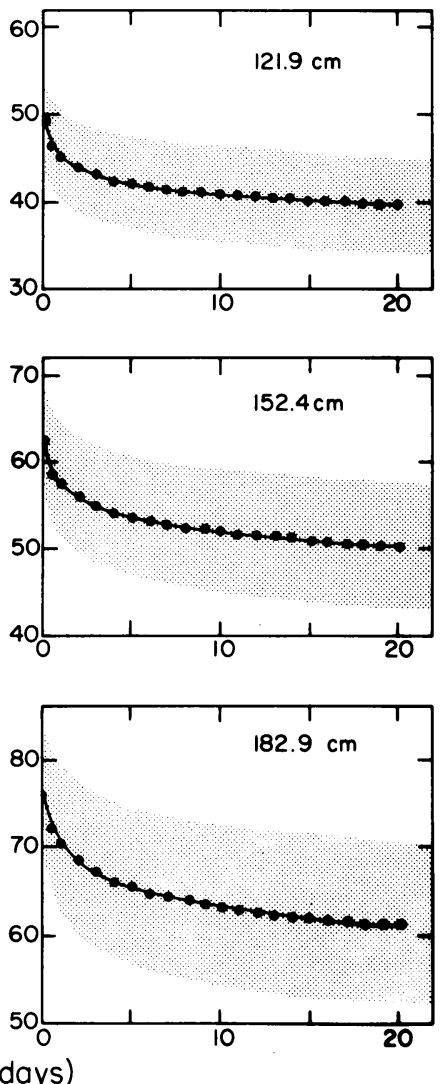

Fig. 7. Measured values of the amount of water stored $\left(\mathrm{cm}^{3} \mathrm{~cm}^{-2}\right)$ in the soil profile from the surface to different depths as a function of time after steady-state infiltration has ceased. Values given the mean values from all plots with shaded areas represent standard deviations of the means. 
TABLE 3

SOIL-WATER CONTENT FOR EACH PLOT AND SOIL DEPTH DURING STEADY-STATE INFILTRATION

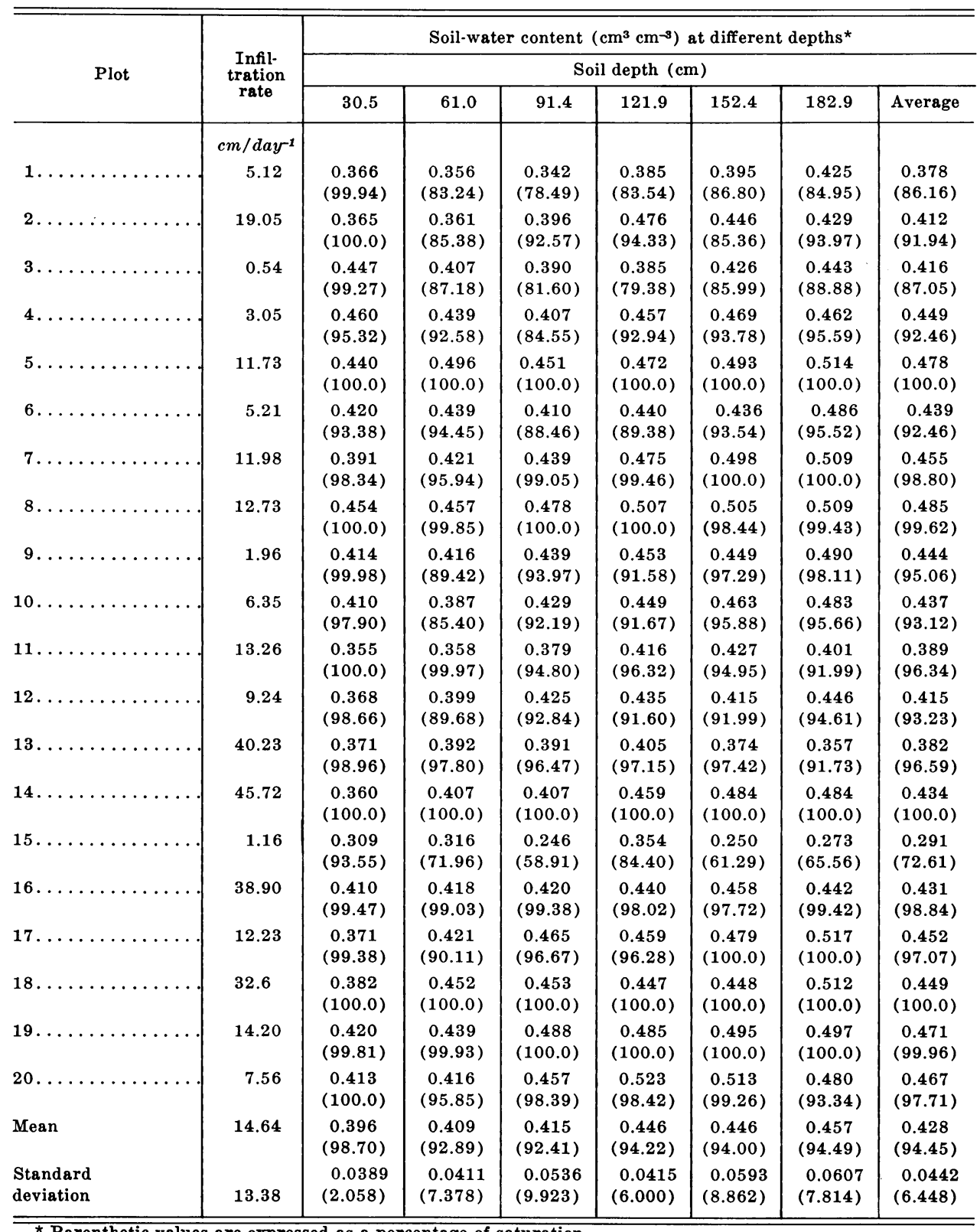

* Parenthetic values are expressed as a percentage of saturation.

tween the lines marked day " 1 " and " 2 " above $121.9 \mathrm{~cm}$ in figure 8 divided by the time increment of 1 day. Figure 9 is a plot of the flux for the six depths aver- aged over the 20 plots. Although the flux decreases rapidly during the first 5 days following the cessation of infiltration, water never stops moving 
out of the profile during the entire experimental period. After 20 days of drainage the flux at $30.5,61.0,91.4$, $121.9,152.4$, and $182.9 \mathrm{~cm}$ depths was $0.0193,0.0398,0.0671,0.0973,0.1275$, and $0.1637 \mathrm{~cm} \mathrm{day-1,}$ respectively.

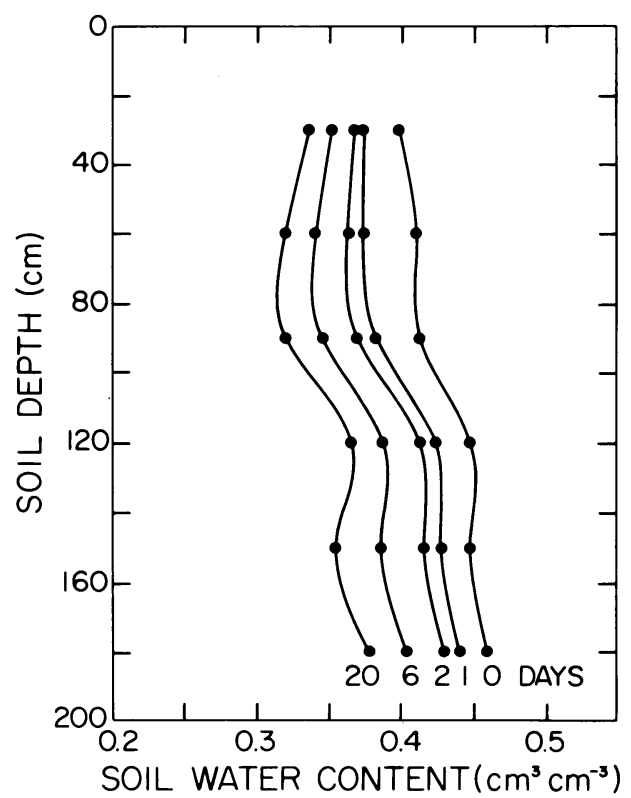

Fig 8. Soil-water-content profiles for the entire field at $0,1,2,6$, and 20 days following the cessation of steady-state infiltration.

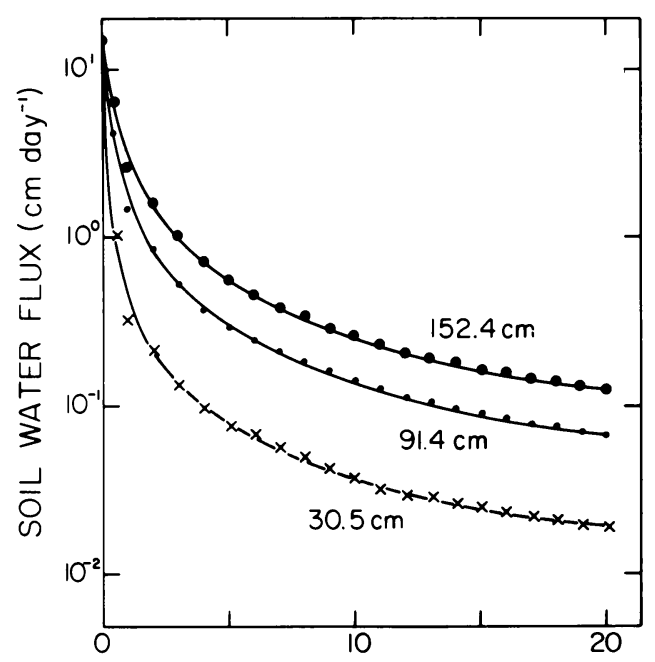

After 20 days the coefficient of variation of the soil-water flux was about 30 per cent. This variability is not insignificant; in terms of the standard deviation of the $121.9 \mathrm{~cm}$ soil depth, it represents $\pm 0.3 \mathrm{~mm}$ per day compared with an average daily evapotranspiration loss of $6 \mathrm{~mm}$. Appendix $J$ gives the flux for each depth and each plot.

The steady-state infiltration, the average soil-water flux for the entire field, was $14.64 \mathrm{~cm} \mathrm{day}^{-1}$ with a standard deviation of the mean equal to 13.38 $\mathrm{cm}$ day $^{-1}$. The infiltration rate ranged from $0.54 \mathrm{~cm} \mathrm{day}^{-1}$ for plot 3 to 45.72 cm day $^{-1}$ for plot 14 . Table 3 gives these values and those of soil-water content for each depth and plot. Inasmuch as the frequency distribution of the soil-water content values for all soil depths (120 values) during steadystate infiltration given in figure 10 satisfies equation [32], its distribution is considered normal.

\section{Hydraulic conductivity}

Measured values of the hydraulic conductivity determined with equation [6] are tabulated for all depths and

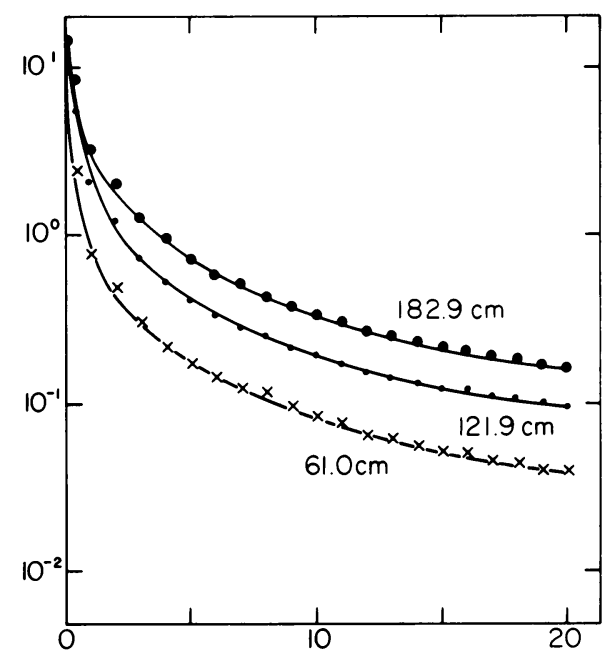

TIME (days)

Fig. 9. Soil-water flux as a function of time after infiltration at six depths for the entire field. 


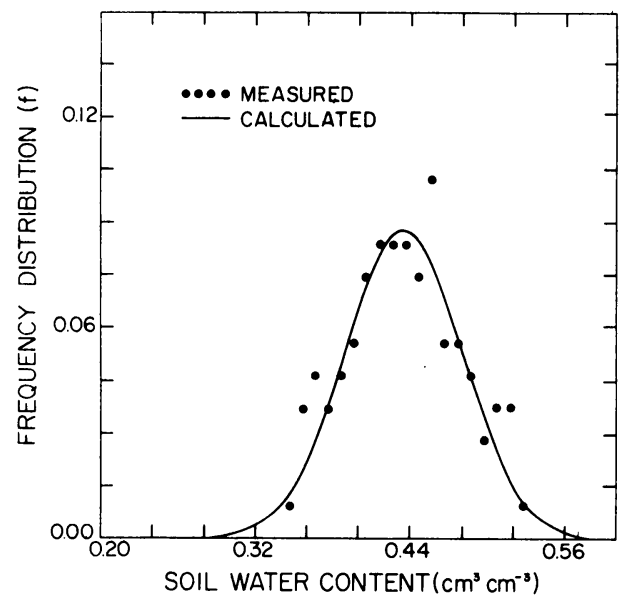

Fig. 10. Measured (120 samples) and calculated frequency distributions for soil-water contents manifested at all soil depths during steady-state infiltration. The curve is described by equation [32] for values of $m$ and $\sigma$ equal to 0.433 and $0.0455 \mathrm{~cm}^{3} \mathrm{~cm}^{-3}$, respectively.

plots in Appendix K. Values of the hydraulic gradient for each depth of each plot are given in Appendix L. A logical question to ask is: "For a specific water content what is the corresponding mean hydraulic conductivity value, and what is the value of its standard deviation?" This is a difficult question to answer. Figure 11 shows two hydraulic conductivity versus soilwater content curves at the $121.9-\mathrm{cm}$ depth for plots 18 and 20. The solid square symbols in the figure represent the values during the steady infiltration. For plot 18, the steady water content was $0.448 \mathrm{~cm}^{3} \mathrm{~cm}^{-3}$ representing 100 per cent of saturation, and for plot 20 it was $0.513 \mathrm{~cm}^{3} \mathrm{~cm}^{-3}$, equivalent to 98.4 per cent of saturation. In other words, for plot 18 at a depth of 121.9 $\mathrm{cm}$ the water content could never exceed $0.448 \mathrm{~cm}^{3} \mathrm{~cm}^{-3}$ while the water content of plot 20 never fell below $0.460 . \mathrm{cm}^{3} \mathrm{~cm}^{-3}$. Under these circumstances, how can data be manipulated to obtain meaningful average hydraulic conductivity and standard deviation values with respect to a specific water content? It is physically meaningless to

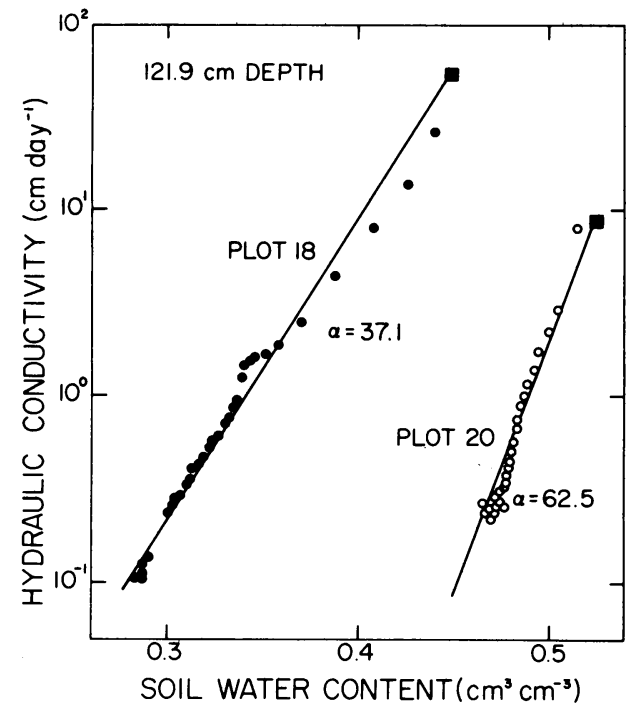

Fig. 11. Hydraulic conductivity as a function of soil-water content measured at a depth of $121.9 \mathrm{~cm}$ in plots 18 and 20 . The solid straight lines approximating measured values stem from equation [15] for the values of $\alpha$ shown. The square symbol represents the steady-state value.

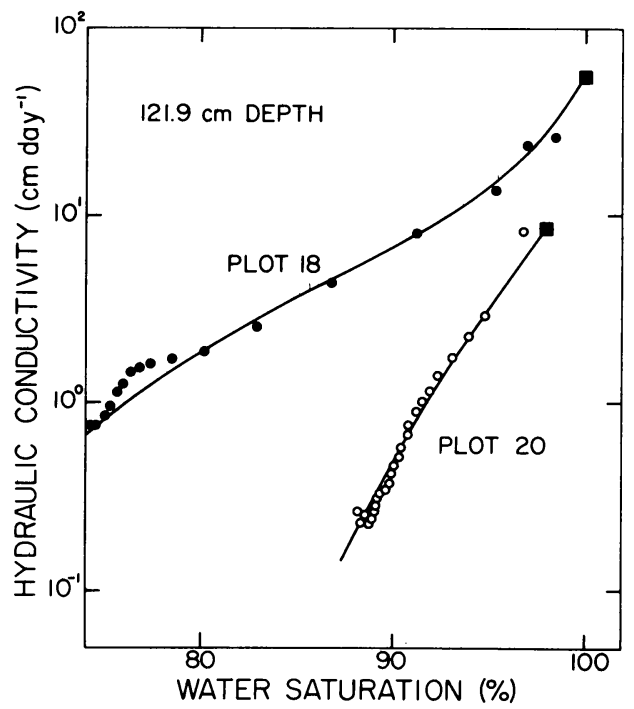

Fig. 12. Hydraulic conductivity as a function of percentage water saturation measured at a depth of $121.9 \mathrm{~cm}$ in plots 18 and 20 . The square symbol represents the steady-state value.

extrapolate the hydraulic conductivity water content curve for plot 18 beyond its saturated water content of 0.448 


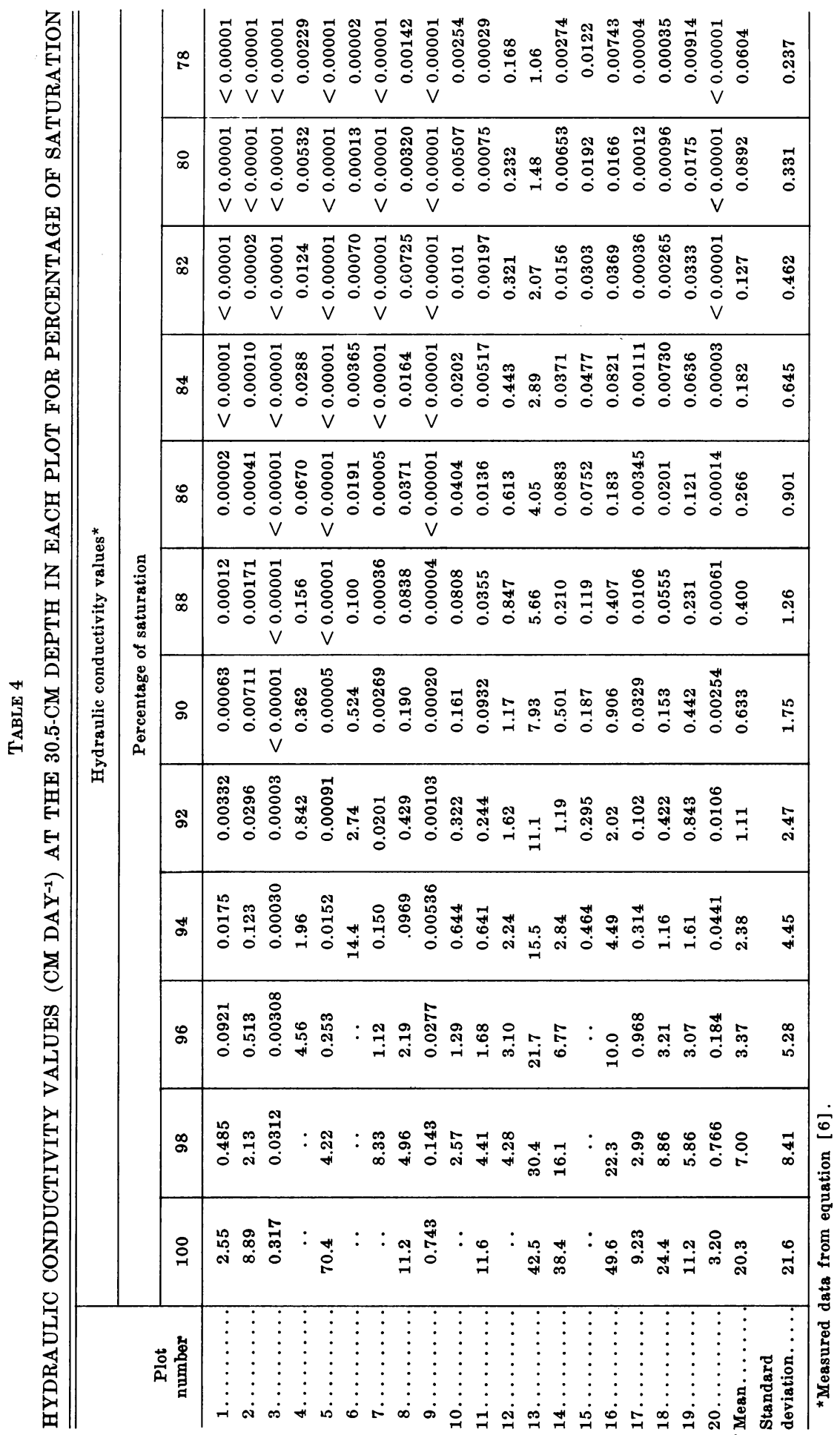




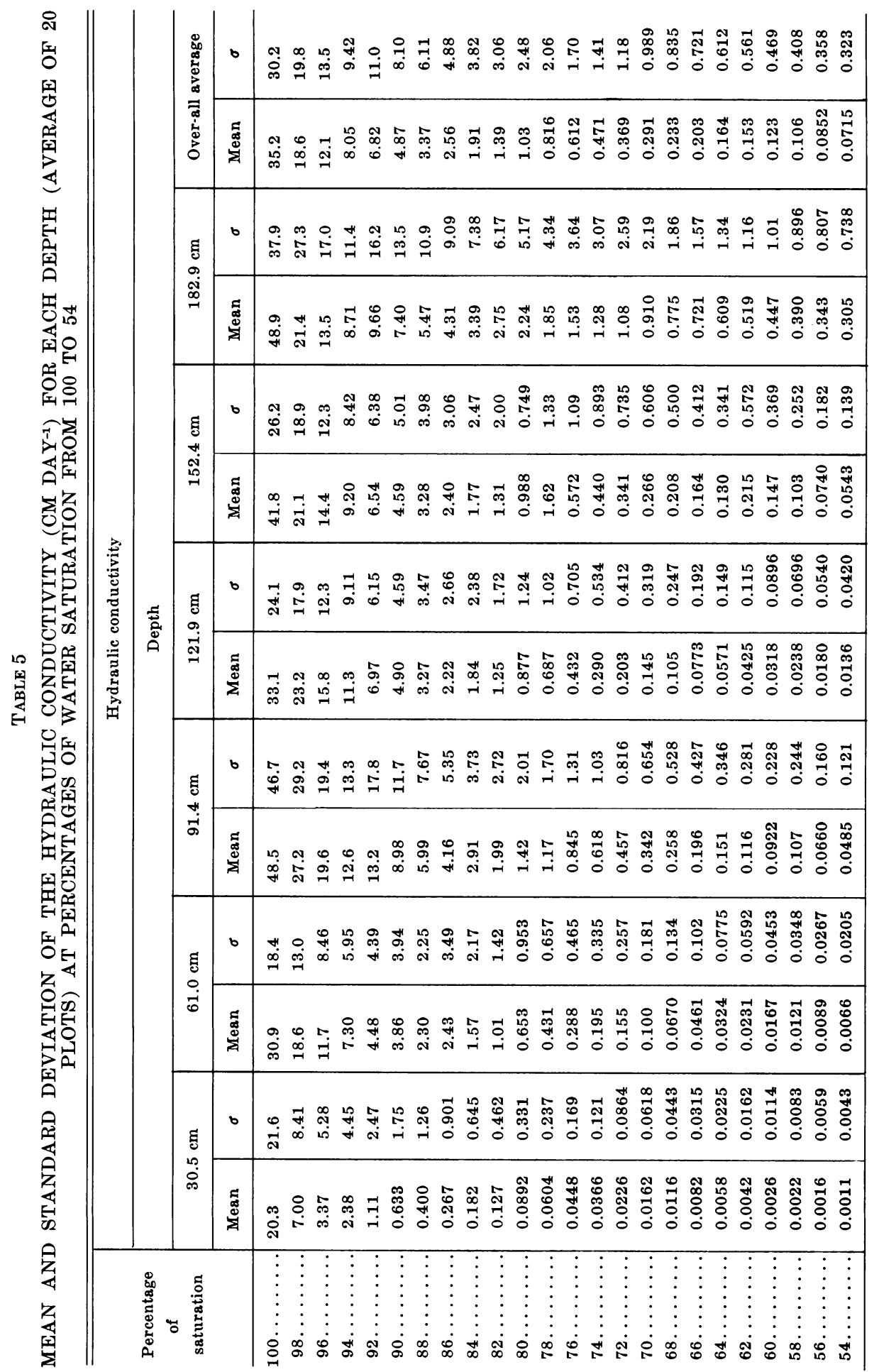


$\mathrm{cm}^{3} \mathrm{~cm}^{-3}$ to a water content of 0.513 $\mathrm{cm}^{3} \mathrm{~cm}^{-3}$ in order to obtain an average value of hydraulic conductivity at the latter value.

We shall show later that the steady infiltration rate is highly correlated to percentage of saturation but does not correlate well with water content. Because of this correlation, it is more meaningful to express the hydraulic conductivity as a function of percentage of saturation. By this ploy, we can vary the values of hydraulic conductivity within the same domain (i.e., between 0 and 100 per cent of saturation) so that we can overcome the difficulty of evaluating the spatial variation of hydraulic conductivity due to the variation in soil-water characteristics. Figure 12 differs from figure 11 by having the hydraulic conductivity plotted against per cent water saturation. Plotting the soil-water content as percentage of saturation shifts the curves along the abscissa but the general shapes of the curves are preserved.

Table 4 lists the values of hydraulic conductivity against the percentage of saturation at the 30.5-cm depth for all plots. In table 4 , any plot which has missing data beyond a certain percentage of saturation implies that for that particular plot the maximum percentage of saturation will never exceed the largest value listed. For example, for plot 4 the maximum percentage of saturation is 96 even under prolonged ponding, and for plot 6 the maximum percentage of saturation is 94 . To evaluate the spatial variations of hydraulic conductivity at certain percentages of saturation, we do not intend to extrapolate beyond the maximum percentage of saturation experimentally observed. We deem this kind of extrapolation impractical because the values have no meaning even if extrapolated. Hence, in table 4 we have only 14 values of hydraulic conductivity instead of 20 at 100 per cent water saturation while at 98 per cent we have 17 values. For water-content values less than saturation, however, values of the hydraulic conductivity were extrapolated. For example, for plot 20 at the 121.9-cm depth (figure 12) measured data for water contents below 88 per cent saturation were not available. In this situation, we linearly extrapolated the semi-log plot of the hydraulic conductivity versus percentage of saturation curve to estimate values of $K$ for water contents below 88 per cent saturation.

Table 5 lists the average hydraulic conductivity and standard deviation values at the six depths, as well as over-all average values for the field. In general, values of the standard deviation exceed those of the mean for all values of percentage of saturation. Figure 13 depicts graphs of hydraulic conductivity versus percentage of water saturation for each soil depth.

The above analysis treated the soil profile as if it were composed of six 30.48-cm layers corresponding to those depths at which measurements were made. An alternative approach can be used for calculating the mean values of the hydraulic conductivity, especially if we wish to use simplified approximate analyses where the field is treated as a homogeneous soil mass. We assume that all experimental measurements within the 150-hectare field are taken at the same time. In other words, 20 measurements are taken at each specified depth for six depths for a total of 120 experimental measurements at a time. We further assume that the measured values of soil-water content and hydraulic conductivity obtained are separate random variables which would be subject to experimental error. Table 6 illustrates how values of the average soil-water content and hydraulic conductivity can be evaluated. This table represents values of $\theta$ and $K$ for each plot measured at $121.9 \mathrm{~cm}$ at times of $0,0.5,1,2,3$, and 4 days. The average values of $\theta$ and $K$ for that 


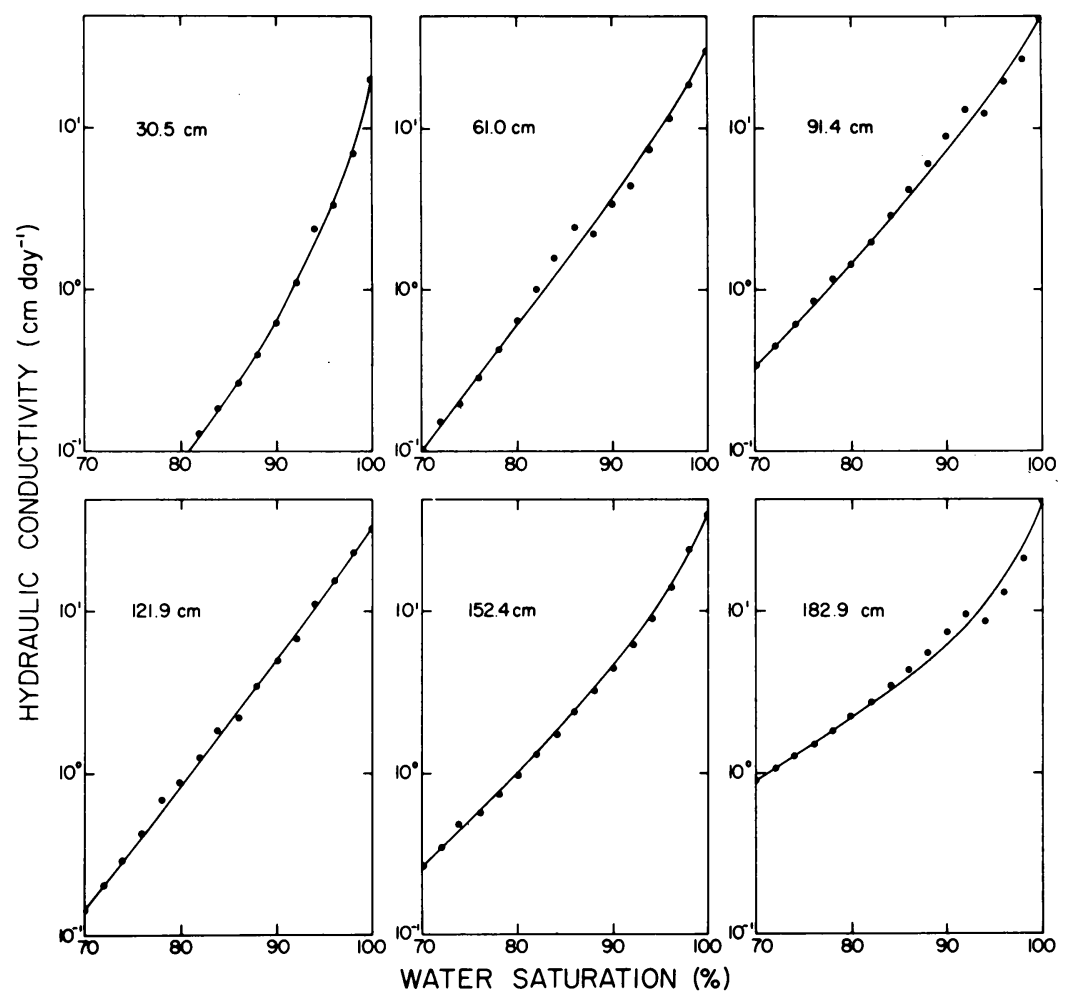

Fig. 13. Measured values of hydraulic conductivity as a function of percentage water satura. tion at six depths over the entire 150-hectare field. Values stem from table 5.

depth over the field for each time are given at the bottom of the table together with their standard deviation values. Such a procedure was followed for all six depths for times up to 20 days following infiltration. Figure 14 shows for each soil depth the average values of hydraulic conductivity versus average soil-water content obtained by such a procedure. These values, together with the standard deviation of the means, are tabulated for each depth and time in table 7. Although these measurements were made on the 20 plots for time periods up to 150 days, measurements were not made on plot 17 past 20 days, and hence the procedure was limited to a 20-day period.

Figure 15 depicts the over-all average hydraulic conductivity versus average soil-water content curve for the entire field. The solid square designates the average steady hydraulic conductivity and water content. Figure 15 clearly displays an exponential relationship between hydraulic conductivity and soil-water content. For approximately every $0.045 \mathrm{~cm}^{3} \mathrm{~cm}^{-3}$ change in soil-water content the hydraulic conductivity changes an order to magnitude. The value $\alpha$ in equation [15] for figure 15 is 57.4. For figure 14 , the values of $\alpha$ for each individual depth at $30.5,61.0,91.4,121.9,152.4$, and $182.9 \mathrm{~cm}$ are $138.6,67.5,56.2,52.2$, 46.9 , and 44.0 , respectively. The values of $\alpha$ decreases with increasing depth.

The frequency function of a lognormal distribution is

$$
f=\frac{1}{\sigma(x-\beta) \sqrt{2 \pi}} \exp \left\{-[\ln (x-\beta)-m]^{2} / 2 \sigma^{2}\right\}
$$




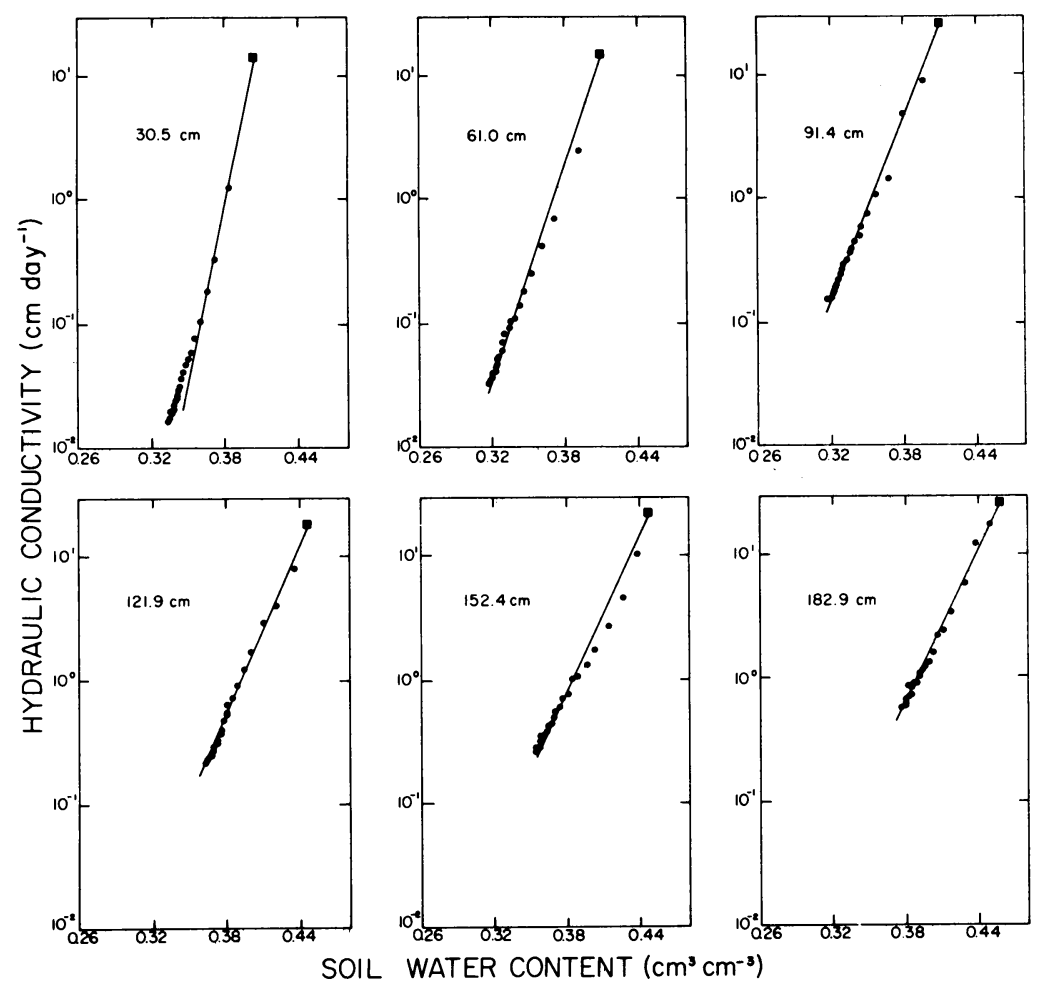

Fig. 14. Measured values of the hydraulic conductivity as a function of soil-water content at six depths over the entire 150-hectare field. Values stem from the procedure illustrated in table 6.

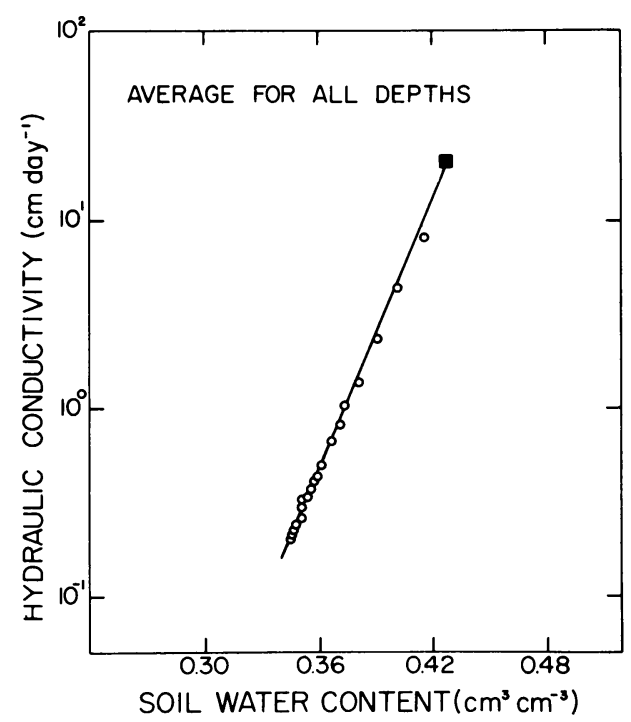

Fig. 15. Treating the entire-150-hectare field as a homogeneous soil to a depth of $182.9 \mathrm{~cm}$, the graph is a plot of average hydraulic conductivity as a function of average soil-water content. The solid line is equation [15] with $\alpha$ equal to 57.4 . for $x>\beta$ and $f=0$ for $x<\beta$, where $\beta$ is any constant to allow $\ln (x-\beta)$ to be normally distributed. Figure 16 depicts the distribution of hydraulic conductivity values measured for steadystate infiltration conditions at 120 positions within the 150-hectare field and that calculated with equation [33] for values of $m, \sigma$ and $\beta$ equal to 2.58, 1.01, and $0 \mathrm{~cm} \mathrm{day}^{-1}$, respectively. Apparently, values of the hydraulic conductivity for steady-state infiltration conditions are log-normally distrib. uted.

\section{Soil-water diffusivity}

Values of the soil-water diffusivity (equation [7]) for each soil depth tabulated in table 8 are plotted as a function of percentage water saturation in figure 17. These values correspond to those of the hydraulic conductivity presented previously in fig- 


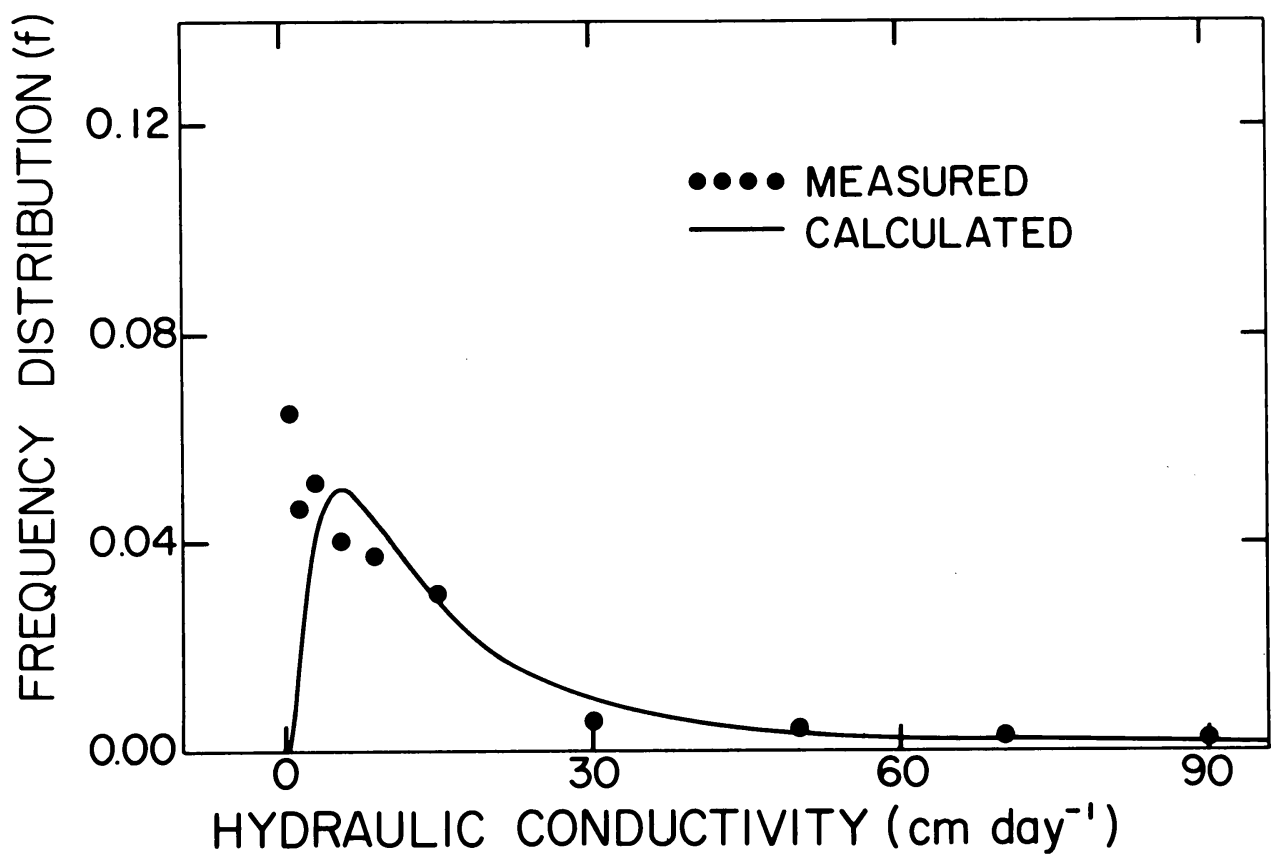

Fig. 16. Measured and calculated frequency distributions for hydraulic conductivity values for steady-state infiltration conditions. The curve is described by equation [33].

ure 13. The standard deviation of the mean soil-water diffusivity is greater than the mean. Values of $D$ for each soil depth calculated from equation [7], using values of $K$ given in figure 14 and the slope of soil-water characteristic curves given in figure 4, are presented in figure 18 and Appendix M. These values plotted as a function of soil-water content rather than percentage of water saturation manifest an exponential relation inasmuch as their curves are nearly linear on the semi-log graph.

Values of the soil-water diffusivity for steady state infiltration conditions measured at 120 positions satisfy equation [33]. These values like thase of the hydraulic conductivity are lognormally distributed.

\section{Hydraulic conductivity: a simple field method}

A simple field method was examined by calculating the hydraulic conduc- tivity with equation [8]. The left-hand side of the equation is an estimate of the soil-water flux at depth $L$ at which the value of $K$ is to be evaluated. Values of the soil-water flux according to equation ([8] are numerically equal to values of the hydraulic conductivity. An example of how well values of $K$ calculated with equation [8] approximate those measured with equation [6] is given in figure 19 for all six depths of plot 1 . The agreement between values is reasonable especially when the standard deviation of the mean measured values for a given water content presented previously in table 7 is considered. On the average, satisfactory agreement was obtained for all 20 plots.

\section{Soil-water diffusivity: a simple field method}

Unlike the above simple methods for estimating the hydraulic conductivity, no estimate of soil-water content or 
TABLE 6

VALUES OF SOIL-WATER CONTENT AND HYDRAULIC CONDUCTIVITY MEASURED AT THE 121.9-CM DEPTH FOR 20 PLOTS DURING A 4-DAY PERIOD

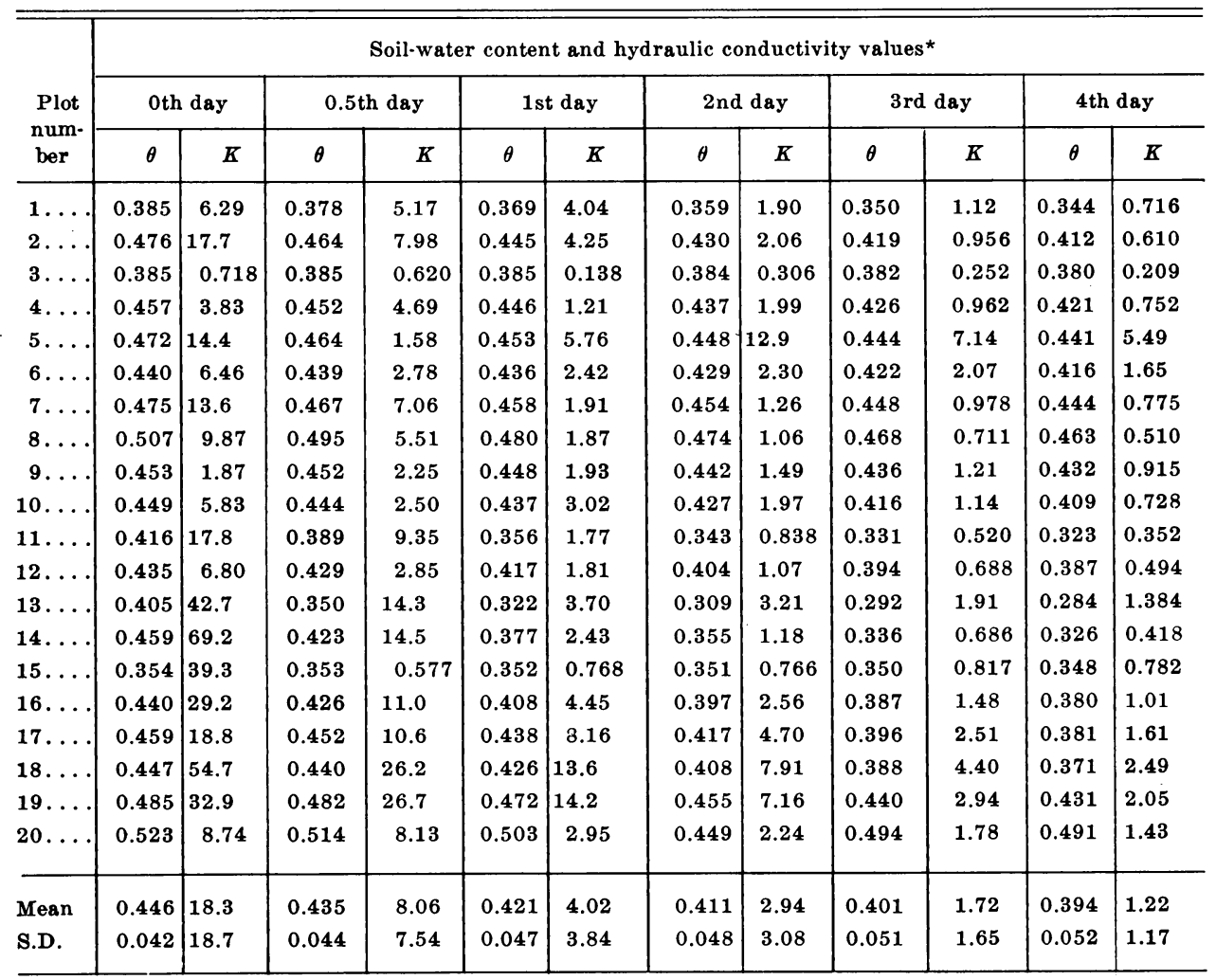

* Values of $\theta$ and $K$ are given in $\mathrm{cm}^{3} \mathrm{~cm}^{-3}$ and $\mathrm{cm} \mathrm{day}^{-1}$, respectively.

average amount of water stored in the profile is required to calculate the soilwater diffusivity from equations [10] or [11]. Equation [10] requires that at least two tensiometers be used to estimate the hydraulic gradient while equation [11] assumes the gradient to be unity. In both cases, a single tensiometer located at depth $\mathrm{L}$ suffices to estimate the value of the left-hand term of either equation. Figure 20 shows both sets of calculated values versus those measured by using equation [7] for all six depths of plot 1 . For each depth the agreement is excellent if the hydraulic gradient is measured (equation [10]), and is more than satisfactory if the more simple equation [11] is used: Tabulated data for the figure and all other plots given in Appendices $\mathrm{M}, \mathrm{N}$, and $\mathrm{O}$ indicate that equation [11] can be used with reasonable success over the entire field.

\section{Hydraulic conductivity from the soil-water characteristic}

Agreement between values of hydraulic conductivity calculated by the equations of Childs and Collis-George and Millington and Quirk and those measured was excellent. Because values calculated by the method of Kunze et al. were nearly identical to those of Millington and Quirk using a matching factor, they are not presented. Marshall's equation was less satisfactory. Except for hydraulic conductivity values 


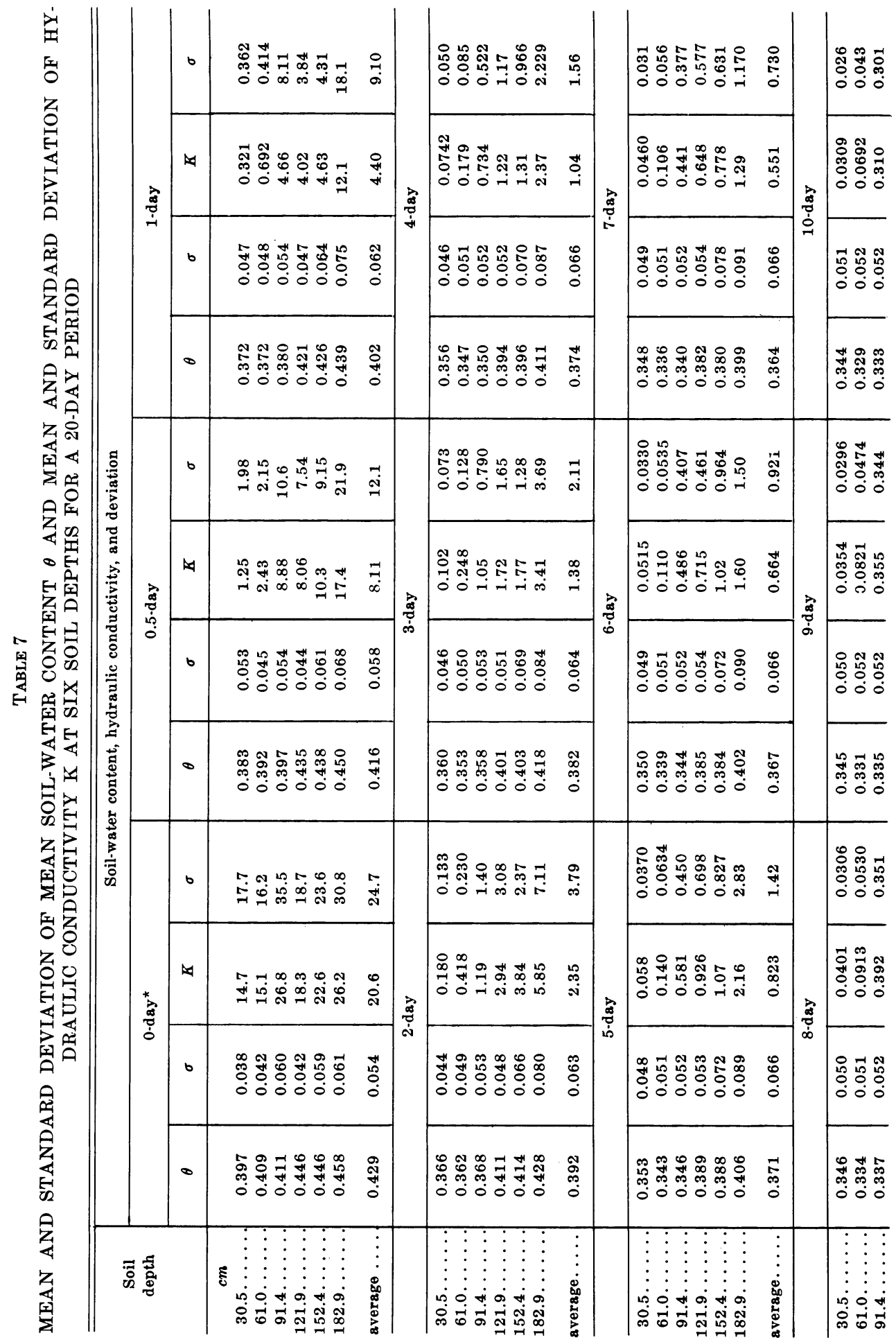




\begin{tabular}{|c|c|c|c|c|c|c|c|}
\hline 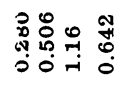 & \multirow{4}{*}{ 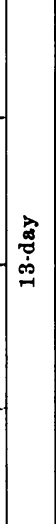 } & 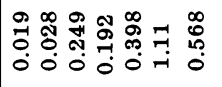 & \multirow{4}{*}{ 密 } & 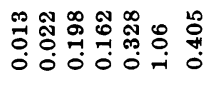 & \multirow{4}{*}{ 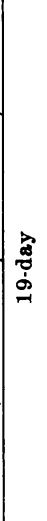 } & 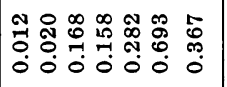 & \\
\hline 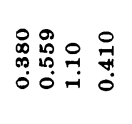 & & 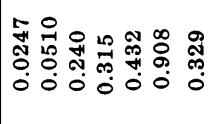 & & 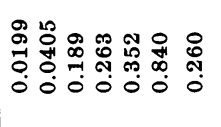 & & 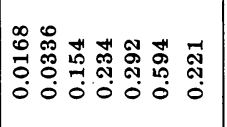 & \\
\hline 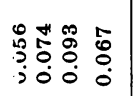 & & 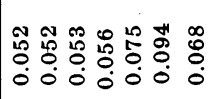 & & 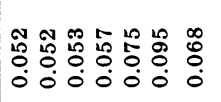 & & 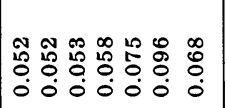 & \\
\hline 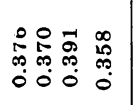 & & 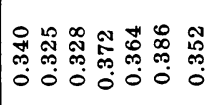 & & 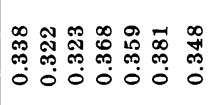 & & 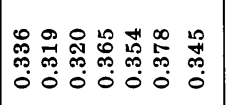 & \\
\hline 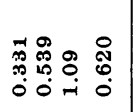 & \multirow{4}{*}{ 离 } & 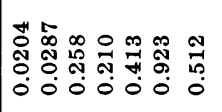 & \multirow{4}{*}{ 宏 } & $\begin{array}{ll} \\
\vdots \\
0\end{array}$ & \multirow{4}{*}{ 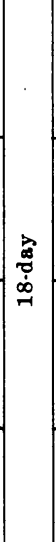 } & 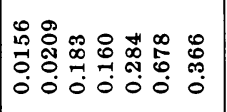 & \\
\hline 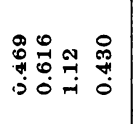 & & 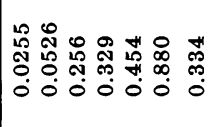 & & 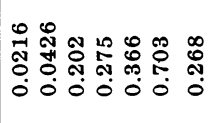 & & 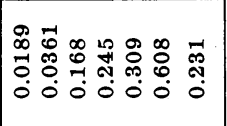 & \\
\hline 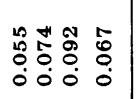 & & 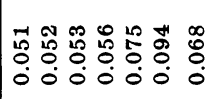 & & 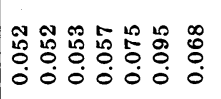 & & 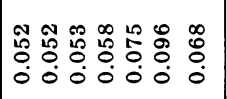 & \\
\hline 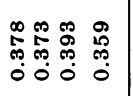 & & 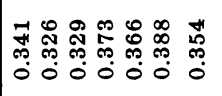 & & 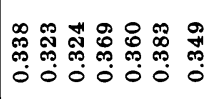 & & 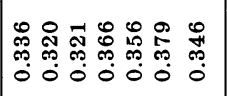 & \\
\hline $\begin{array}{llll}-1 & 0 & & 0 \\
0 & 0 & 0 \\
0 & 0 & 0 & 0 \\
0 & 0 & 0 \\
0 & 0 & -1 & 0\end{array}$ & \multirow{4}{*}{ 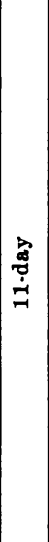 } & 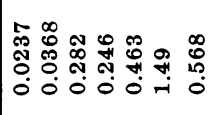 & \multirow{4}{*}{ 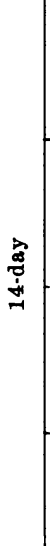 } & 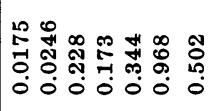 & \multirow{4}{*}{ 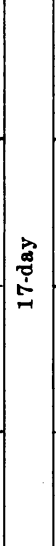 } & 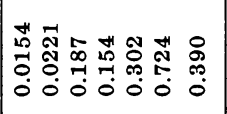 & 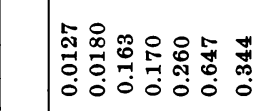 \\
\hline 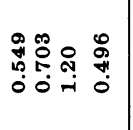 & & 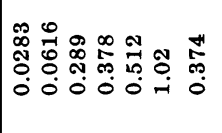 & & 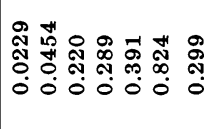 & & 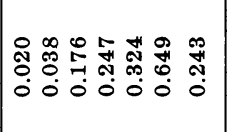 & 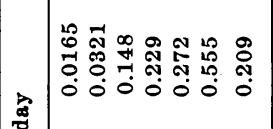 \\
\hline 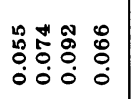 & & 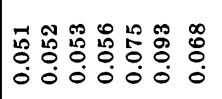 & & 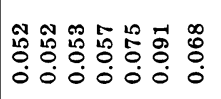 & & 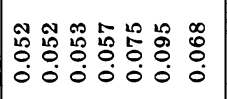 & 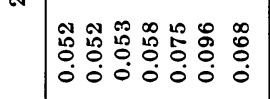 \\
\hline $\begin{array}{llll}0 & 0 & 0 \\
0 & 0 & 0 \\
0 & 0 & 0 \\
0 & 0 & 0 \\
0 & 0 & 0 \\
0 & 0 & 0 & 0 \\
0 & 0 & 0\end{array}$ & & 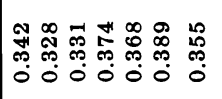 & & 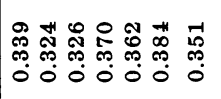 & & 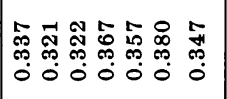 & 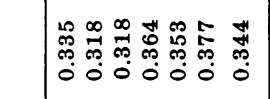 \\
\hline 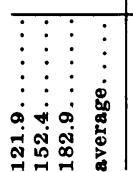 & & 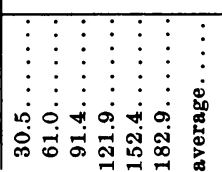 & & 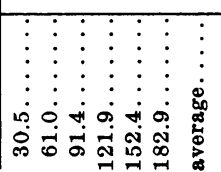 & & 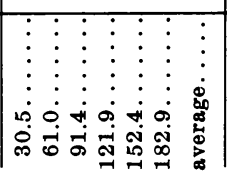 & 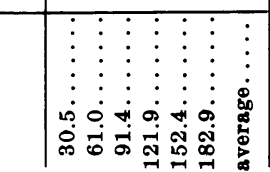 \\
\hline
\end{tabular}




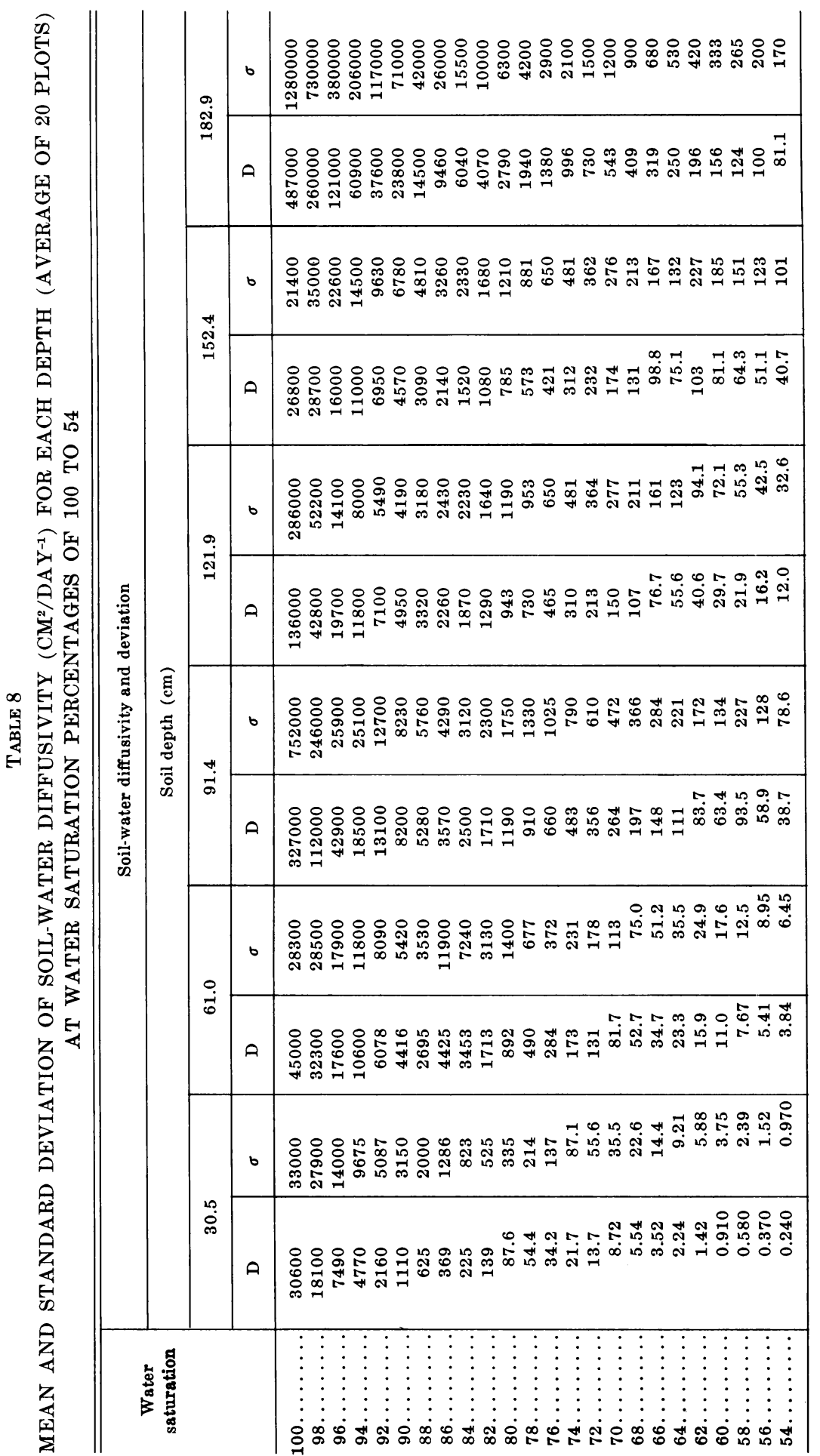




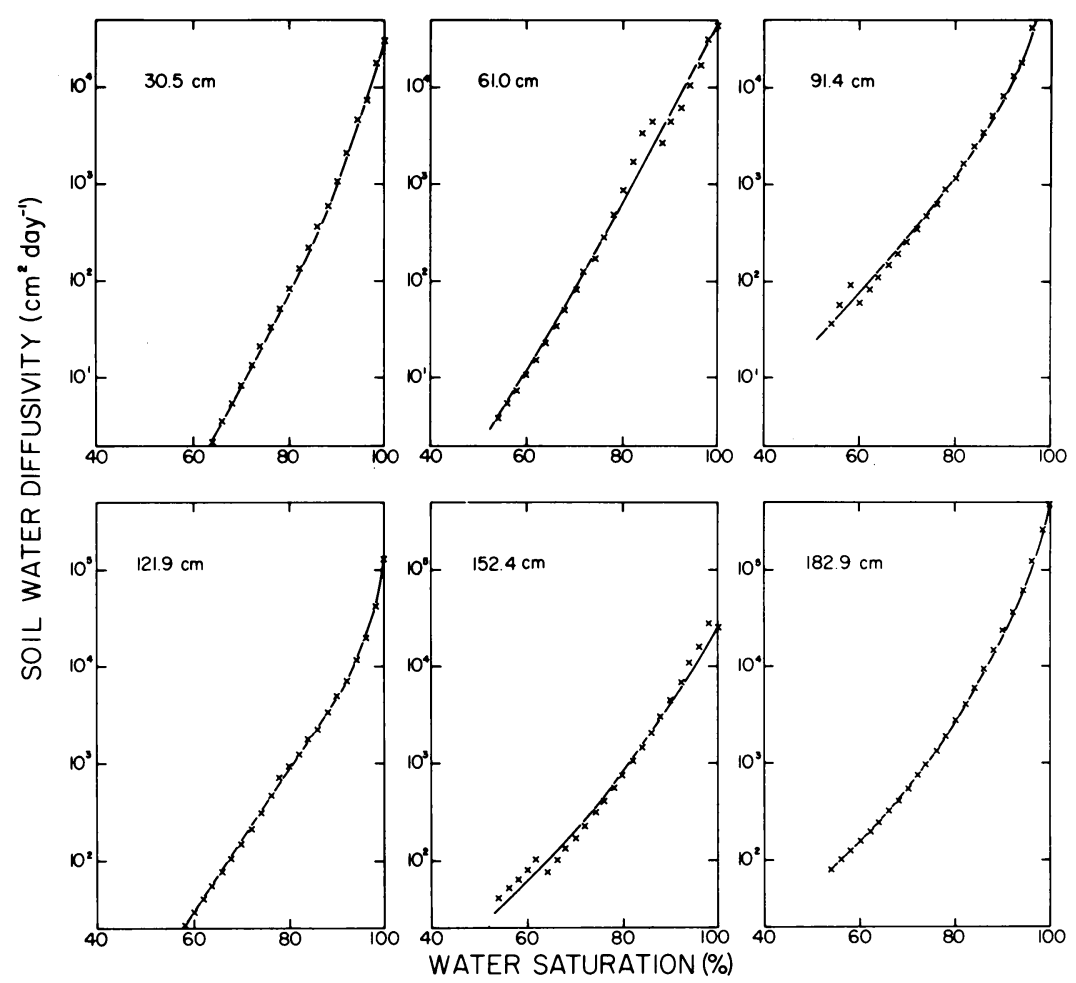

Fig. 17. Measured values of soil-water diffusivity as a function of percentage water saturation at six depths over the entire 150-hectare field. Values stem from equation [7].

calculated by the method of Kunze, et al., figure 21 shows graphs of calculated versus measured values for each of the six depths averaged over the 20 plots. Although the agreement between calculated and measured values is less satisfactory at the shallower depths, results in general indicate that the method proposed (using either of the former equations together with a steady-state infiltration matching factor) provides a satisfactory means of evaluating hydraulic conductivity properties of a field soil. By laboratory measuring the soil-water characteristic curve in the soil cores taken from the field, values of the hydraulic conductivity may be ascertained.

\section{Estimated soil-water flux}

The applicability of equations [15] and [17] to predict the soil-water flux across a particular depth will be presented first in detail for two plots, and then for the entire field. The two straight lines in figure 11 represent the exponential approximation (equation [15]) to the measured values of $K$ for the 121.9-cm depth of plots 18 and 20 . The value of $\alpha$ for plot 18 is 37.1 and for plot 20 is 62.5. The straight line in figure 11 is purposely forced through the solid square symbol which denotes the values of $K_{o}$ and $\theta_{o}$ in equation [15]. Figure 22 shows the calculated and measured soil-water flux at the 121.9-cm depth as a function of time following the cessation of infiltration for plots 18 and 20. The solid and broken lines were obtained from equation [17] with the solid and open circles being measured values. It is obvious from figure 22 that the agreement between theoretical and measured values is good for plot 18 


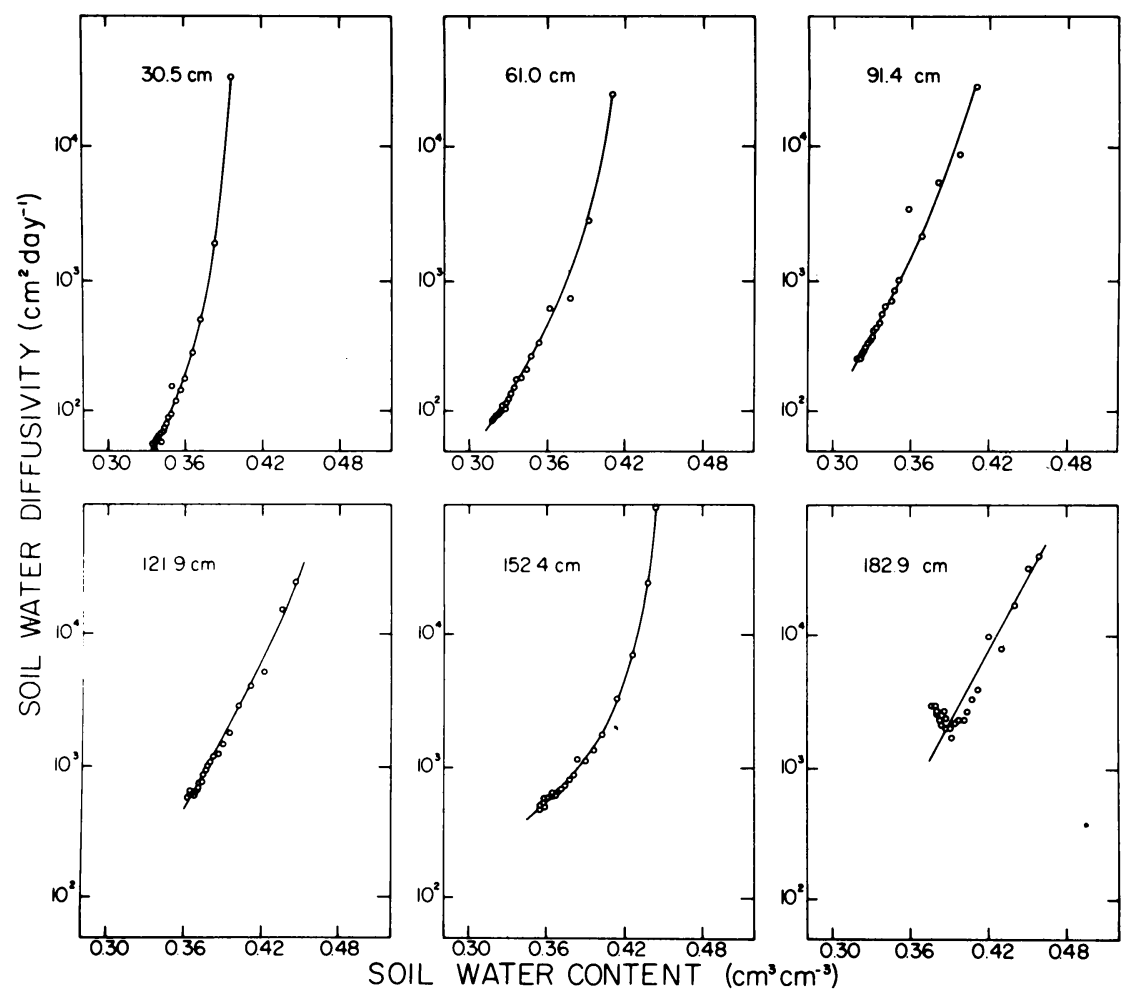

Fig. 18. Soil-water diffusivity versus soil-water content stemming from values of $\mathrm{K}$ in figure 14 and the slopes of the soil-water characteristic curves in figure 4.
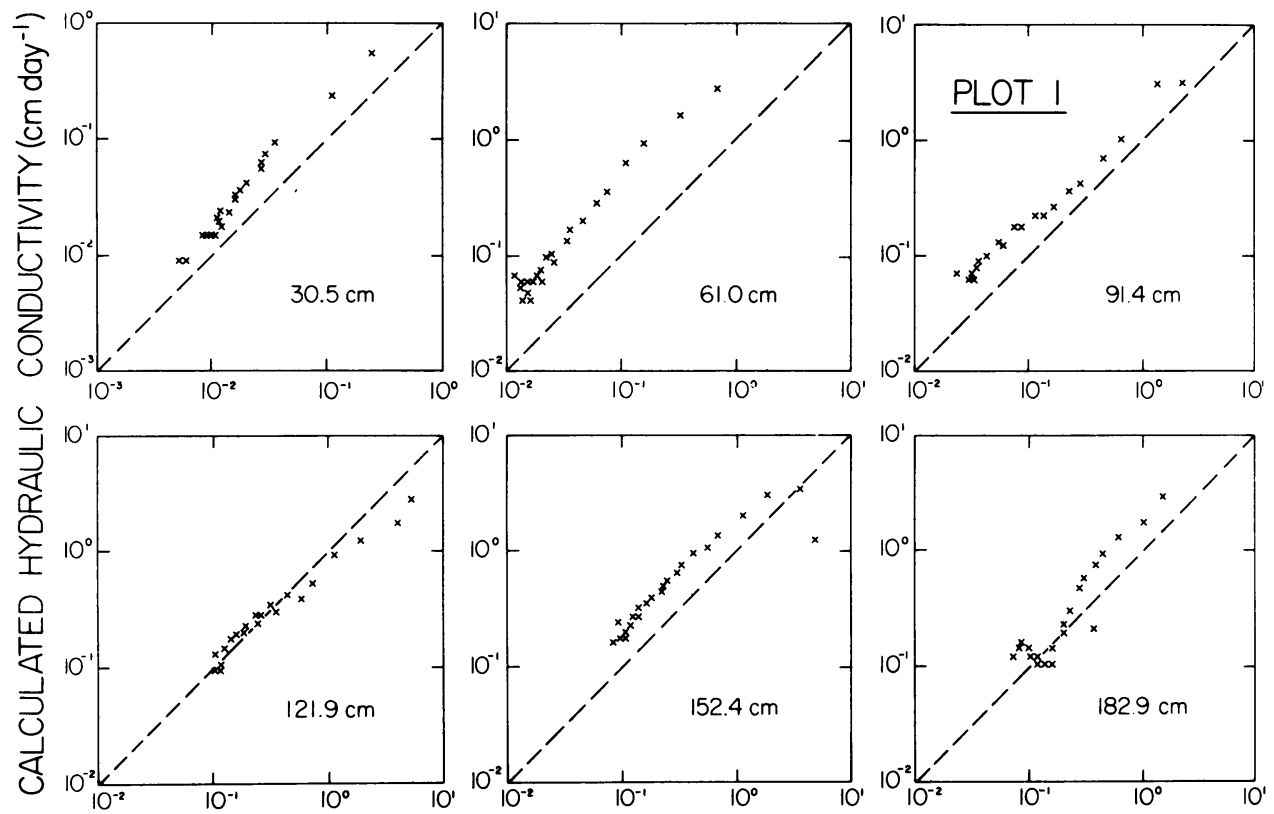

MEASURED HYDRAULIC CONDUCTIVITY ( $\mathrm{cm}^{\left.-10^{-1}\right)}$

Fig. 19. Values of hydraulic conductivity calculated with the assumption that the hydraulic gradient is unity (equation [8]) versus those measured for each depth in plot 1 with equation [6]. 

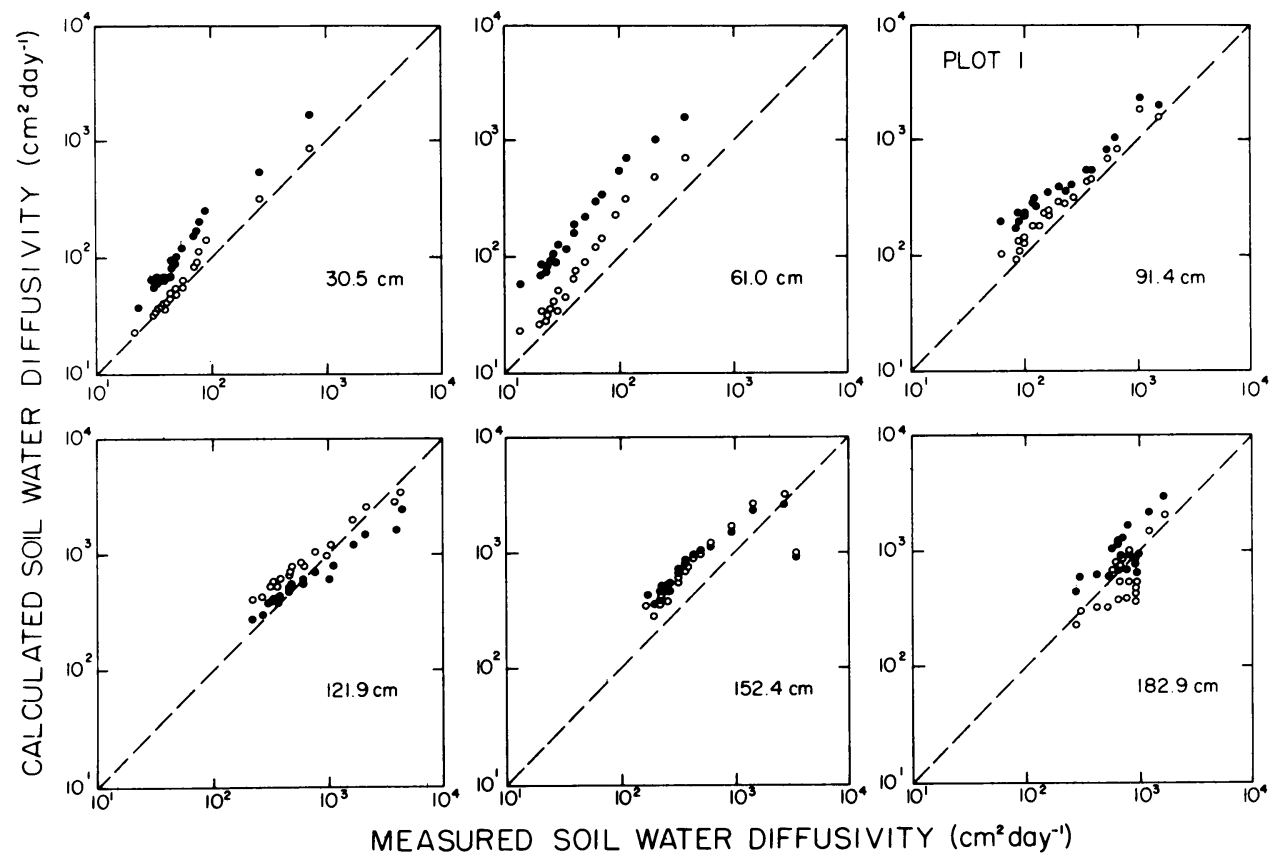

Fig. 20. Graphs of calculated values of soil-water diffusivity (open circles for equation [10] and closed circles for equation [11]) versus measured values for the six soil depths of plot 1.
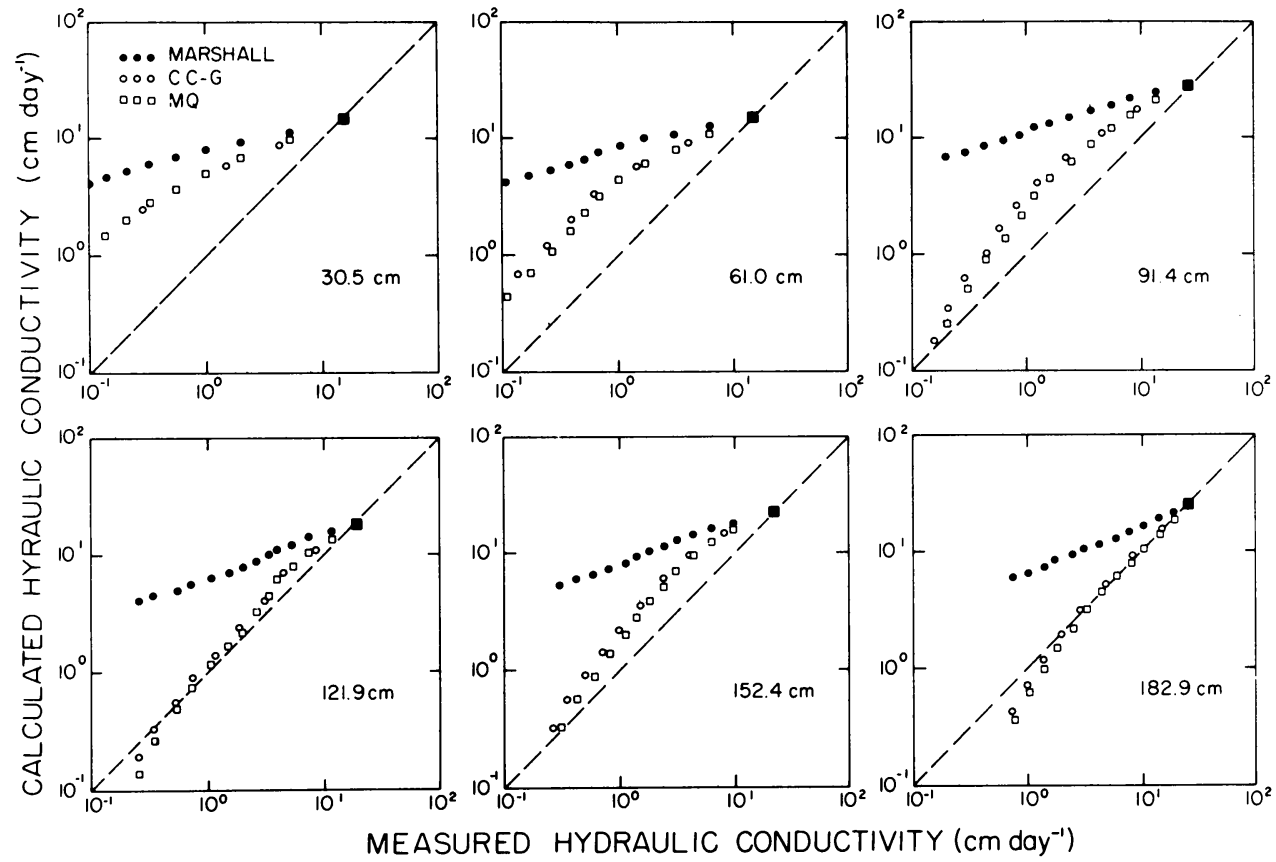

Fig. 21. Graphs of calculated values of the hydraulic conductivity versus measured values for six soil depths averaged for the entire field. Calculated values are matched with those measured for steady-state infiltration conditions. 


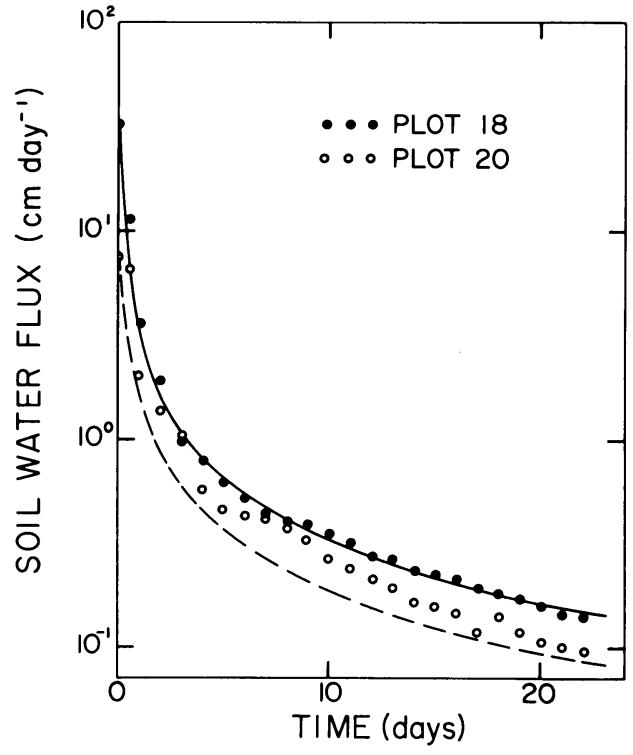

Fig. 22. Calculated (equation [17]) and measured values of soil-water flux at the 121.9cm depth for plots 18 and 20 versus time following the cessation of infiltration. but somewhat less satisfactory for plot 20. Considering various factors which affect field measurements, plus the assumptions involved in equations [15] and [17], the agreement between theorectical and measured values is acceptable. If equation [17] is integrated with respect to time for plot 20 , the total amount of drainage water calculated to leave the $121.9-\mathrm{cm}$ depth during the first 22 days following infiltration was $8.85 \mathrm{~cm}$, while that measured was $11.81 \mathrm{~cm}-\mathrm{a}$ difference of less than $3 \mathrm{~cm}$ for the 22-day drainage period.

If equations [15] and [17] can be applied reasonably well to predict the soil-water behavior of individual plots, how well do they apply to the field? The values of $K_{o}, \theta_{o}$, and $\alpha$ derived from the average value of $K$ versus $\theta$ for the 150-hectare field to a depth of $182.9 \mathrm{~cm}$ are required. These values
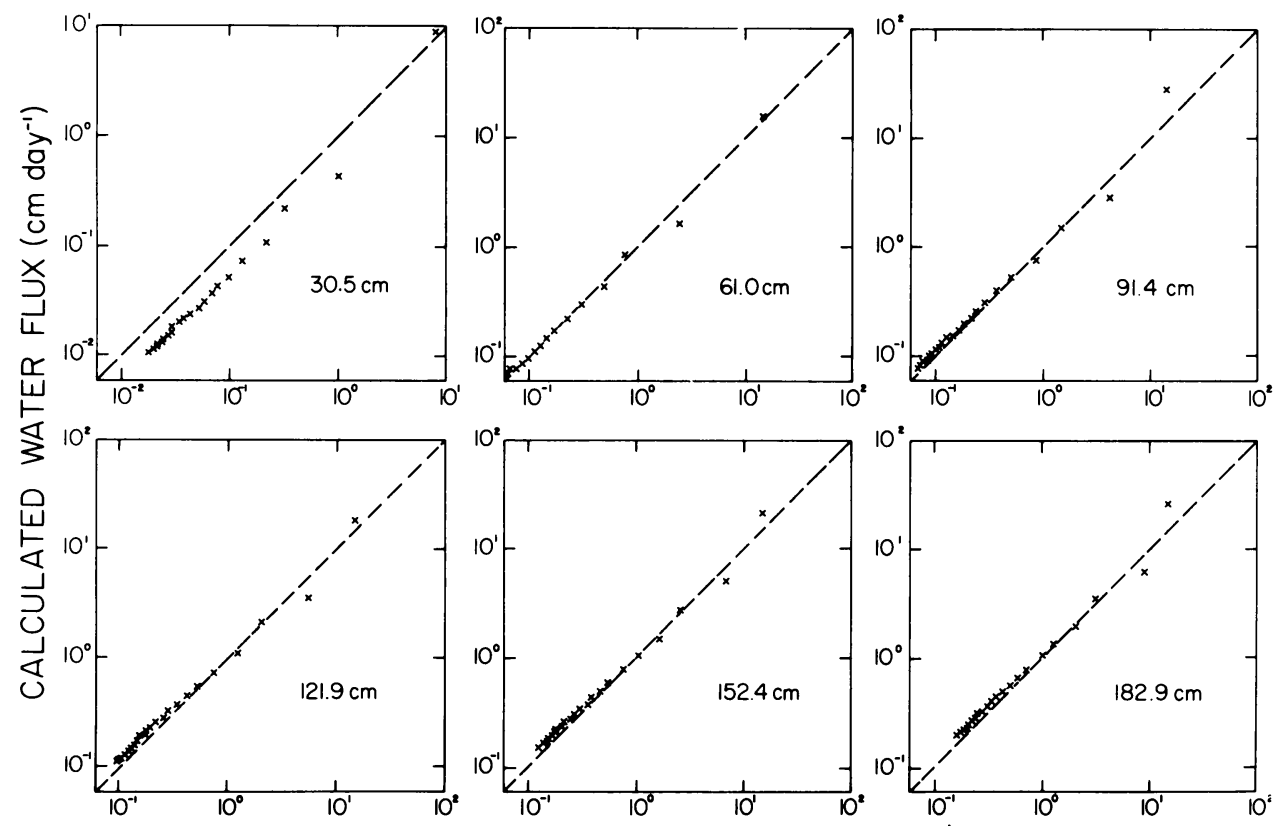

Fig. 23. Calculated (equation [17]) versus measured values of the soil-water flux for the six soil depths over the entire field for 0 to 20 days following cessation of infiltration.

given in figure 15 are $20.62 \mathrm{~cm} \mathrm{day}^{-1}$, is simply the slope of the curve. Figure $0.4286 \mathrm{~cm}^{3} \mathrm{~cm}^{-3}$, and 57.42 , respectively. The values of $\alpha$ in equation [15] 23 shows theoretical and measured values of the soil-water flux at the six 
depths for the field. The best agreement between the calculated and experimental values is at the $121.9-\mathrm{cm}$ depth. At the shallow depth, equation [17] tends to overestimate the soilwater flux and at deeper depths it underestimates it. In view of the magnitude of standard deviation presented in table 9 the theoretical values match the measured values reasonably well.

\section{Detailed analysis of soil-water profiles}

Table 10 gives the measured and calculated soil-water contents at each depth for plot 1 for the first 10 days after infiltration. Calculated values $C$ stem from the solution of equation [26] taking into account the different
$K(\theta)$ and $h(\theta)$ distributions for each $30.48 \mathrm{~cm}$ depth throughout the $\mathbf{1 8 2 . 9}$ $\mathrm{cm}$ profile. Calculated values $\mathrm{E}$ are those estimated with equation [16] assuming a unit hydraulic gradient and the same exponential $K(\theta)$ relation for the entire profile to depth $L$ where the value of $\theta$ is ascertained. Although both methods of calculation yield values in close agreement with those measured, considering the effort required for the numerical analysis even without the extra complication of hysteresis sometimes included in soil-water characteristic analysis, the simplified analysis using equation [16] is entirely satisfactory, especially in view of the spatial variability of soil-water content measurements.

\section{DISCUSSION}

In an attempt to ascertain whether or not any simple relationships exist between soil physical properties measured in the laboratory or field and the movement or retention of water in the field, correlations were made statistically wherever possible.

\section{Steady infiltration rate and steady hydraulic conductivity}

Table 11 gives the correlation coefficients for steady-state infiltration rate and percentage of clay, and percentage of sand, and soil-bulk density. From the large values of the correlation coefficient it is apparent that the steady-state infiltration rate is correlated significantly to percentage of sand, percentage of clay, and bulk density at the 91.4 and $121.9-\mathrm{cm}$ depths. The low values of the correlation coefficient for these properties at $30.4,61.0,152.4$, and $182.9 \mathrm{~cm}$ suggest that at these depths the percentage of sand, percentage of clay, and bulk density exert no significant influence on the infiltration rate. The upper portion of the soil profile down to a depth of $60 \mathrm{~cm}$ is disturbed by farming operations. The soil properties at depths greater than $120 \mathrm{~cm}$ appear to have little influence on the redistribution of soil water. Throughout this study, it was apparent that calculations and measurements made for the 91.4 and 121.9cm depths were the most satisfactory, even though marked differences in physical properties were not manifested at these depths.

Table 12 gives correlation coefficients for steady-state hydraulic conductivity and percentage of clay, percentage of sand and soil-bulk density. As with the steady-state infiltration rate, the steady-state hydraulic conductivity is correlated significantly (1 per cent level) at the 91.4 and $121.9-\mathrm{cm}$ depths. The small values of the correlation coefficient for these properties at 30.4, $61.0,152.4$, and $182.9 \mathrm{~cm}$ suggest that at these depths and for these percentage of sands, percentages of clay and of bulk density exert no significant influence on the steady hydraulic conductivity. When all depths and plots are combined to give 120 separate measurements rather than the 20 meas- 


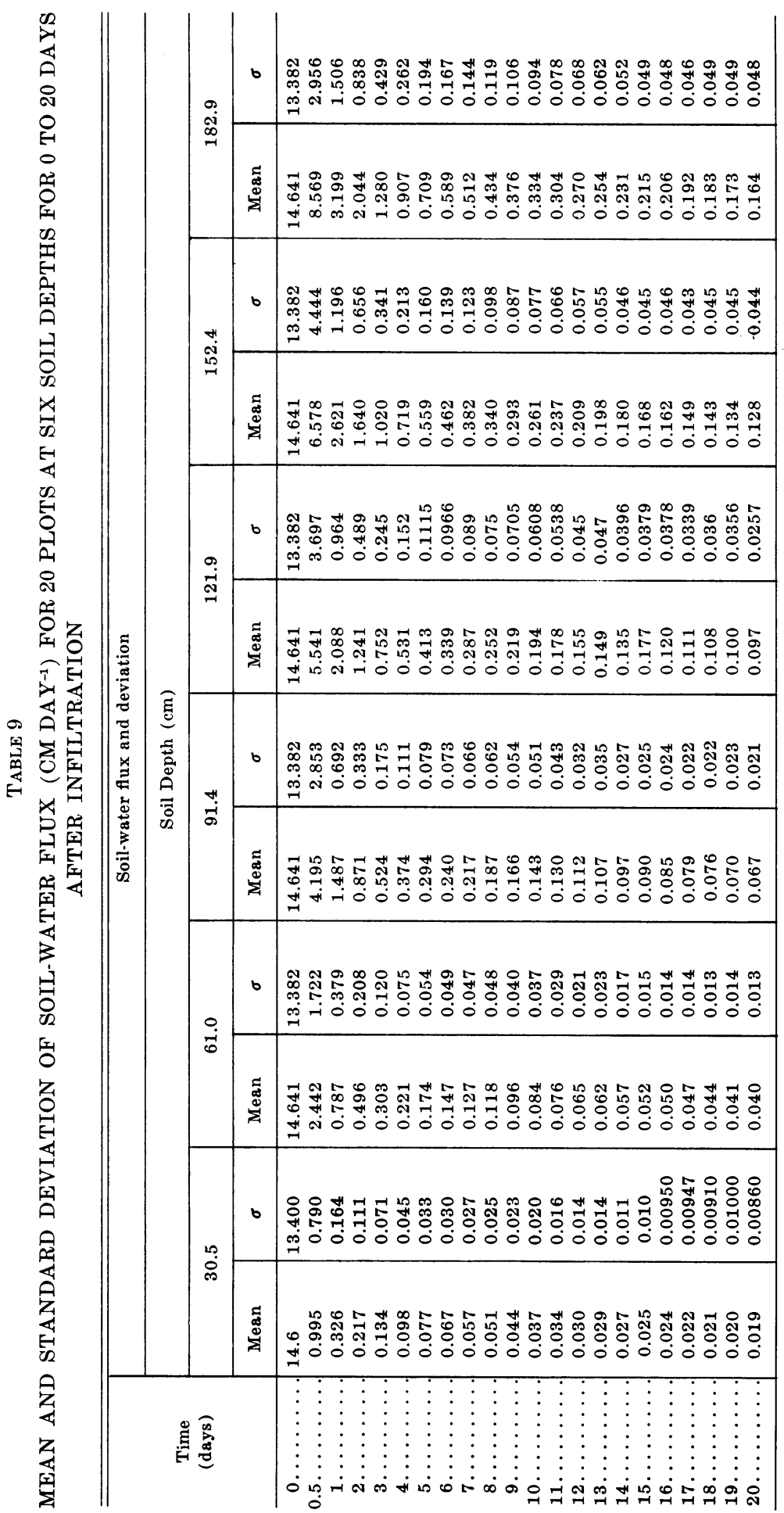




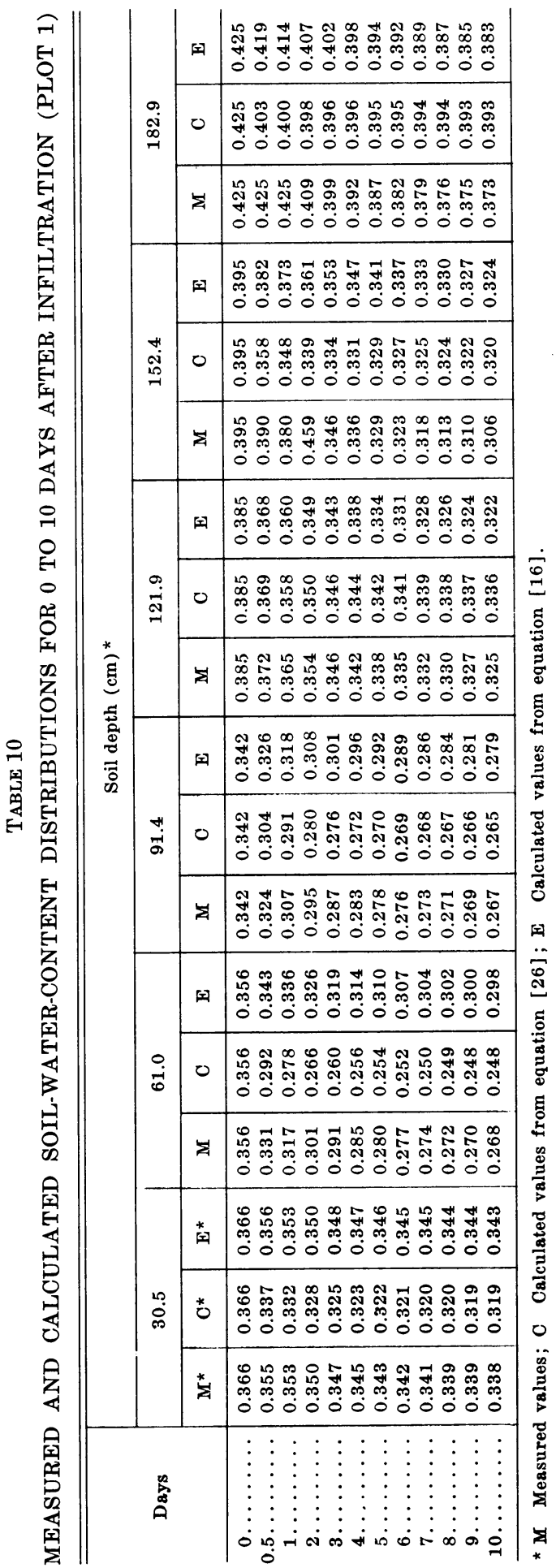


TABLE 11

CORRELATION COEFFICIENTS BETWEEN STEADY INFILTRATION RATE AND PERCENTAGE OF CLAY, PERCENTAGE OF SAND, AND BULK DENSITY

\begin{tabular}{c|c|c|c|c}
\hline \multirow{2}{*}{$\begin{array}{c}\text { Soil } \\
\text { depth }\end{array}$} & \multicolumn{4}{|c}{ Correlation coefficient } \\
\cline { 2 - 5 } & Clay & Sand & $\begin{array}{c}\text { Bulk } \\
\text { density }\end{array}$ & $\begin{array}{c}\text { Sample } \\
\text { size }\end{array}$ \\
\hline cm & & & & 20 \\
$30.5 \ldots \ldots \ldots \ldots \ldots$ & -0.447 & 0.468 & 0.125 & 20 \\
$61.0 \ldots \ldots \ldots \ldots$ & -0.416 & 0.408 & 0.272 & 20 \\
$91.4 \ldots \ldots \ldots \ldots$ & -0.501 & 0.470 & 0.518 & 20 \\
$121.9 \ldots \ldots \ldots \ldots$ & -0.524 & 0.492 & 0.615 & 20 \\
$152.4 \ldots \ldots \ldots \ldots$ & -0.366 & 0.233 & 0.263 & 20 \\
$182.9 \ldots \ldots \ldots \ldots$ & -0.367 & 0.172 & 0.379 & \\
\hline
\end{tabular}

TABLE 12

CORRELATION COEFFICIENT BETWEEN STEADY-STATE HYDRAULIC CONDUCTIVITY $K_{o}$ AND PERCENTAGE OF CLAY, PERCENTAGE OF SAND, AND BULK DENSITY

\begin{tabular}{c|c|c|c|c}
\hline \multirow{2}{*}{$\begin{array}{c}\text { Soil } \\
\text { depth }\end{array}$} & \multicolumn{4}{|c}{ Correlation coefficient } \\
\cline { 2 - 5 } & Clay & Sand & $\begin{array}{c}\text { Bulk } \\
\text { density }\end{array}$ & $\begin{array}{c}\text { Sample } \\
\text { size }\end{array}$ \\
\hline$c m$ & & & & \\
$30.5 \ldots \ldots \ldots \ldots \ldots$ & -0.116 & 0.190 & -0.121 & 20 \\
$61.0 \ldots \ldots \ldots \ldots \ldots$ & -0.230 & 0.287 & 0.213 & 20 \\
$91.4 \ldots \ldots \ldots \ldots \ldots$ & -0.519 & 0.546 & 0.474 & 20 \\
$121.9 \ldots \ldots \ldots \ldots \ldots$ & -0.681 & 0.644 & 0.571 & 20 \\
$152.4 \ldots \ldots \ldots \ldots \ldots$ & -0.430 & 0.336 & 0.180 & 20 \\
$182.9 \ldots \ldots \ldots \ldots$ & -0.389 & 0.118 & 0.403 & 20 \\
entire & $-\ldots . . \ldots \ldots \ldots$ & 0.238 & 0.129 & 120 \\
\hline
\end{tabular}

urements available for each depth, correlation between steady hydraulic conductivity and the clay fraction is significant at the 1 per cent level and the correlation coefficient for the sand fraction represents 5 per cent significance. Correlation between bulk density and steady-state hydraulic conductivity is not significant on the combined samples. The silt fraction does not correlate significantly with either steady-state infiltration or steady-state hydraulic conductivity.

Table 13 gives correlation coefficients between steady-state infiltration rate and steady water content, as well as the correlation coefficients between steady-state infiltration rate and steady-state per cent saturation. There are two separate sets of correlation coefficients in table 13-one to test the linear relationship between the variables, and the other to test the degree of logarithmic dependence of the variables. The small values for the correlation coefficients indicate that the steady-state infiltration rate is not linearly related to the steady-state soilwater content. The data in table 13 indicate that there is some tendency toward an exponential dependence of the steady-state infiltration rate and the steady-state water content at the 91.4 and $121.9 \mathrm{~cm}$ depths, although the correlation is not sufficiently high to be significant. In contrast to the linear 
comparison, the logarithmic relation in table 13 indicates a strong exponential dependence between the infiltration rate and percentage of saturation. For a sample size of 20 , based on significant levels of 5 per cent, 2 per cent, 1 per cent, the correlation coefficients need to be equal to $0.444,0.515,0.561$, and 0.679 , respectively. The relationship between the logarithm of the steady- state infiltration rate and the steadystate per cent saturation at the $121.9-\mathrm{cm}$ depth is significant at the 1 per cent level, indicating that there is almost a complete correspondence between these two values. The data in table $13 \mathrm{dem}$ onstrate that for field measurements the use of percentage of saturation is superior to soil-water content when describing soil-water movement. The per-

TABLE 13

CORRELATION COEFFICIENT BETWEEN STEADY-STATE WATER CONTENT $\boldsymbol{\theta}_{0}$

AND LINEAR AND LOGARITHMIC STEADY INFILTRATION RATE $I_{o}$ AND

BETWEEN STEADY-STATE PERCENTAGE OF SATURATION $S_{o}$ AND LINEAR AND LOGARITHMIC STEADY-STATE INFILTRATION RATE

\begin{tabular}{c|c|c|c|c|c}
\hline \hline \multirow{2}{*}{$\begin{array}{c}\text { Soil } \\
\text { depth }\end{array}$} & \multicolumn{4}{|c|}{ Correlation coefficient } & \\
\cline { 2 - 6 } & $\theta_{o}$ vs $I_{o}$ & $\theta_{o}$ vs ln $I_{o}$ & $S_{o}$ vs $I_{o}$ & $S_{o}$ vs $\ln I_{o}$ & $\begin{array}{c}\text { Sample } \\
\text { size }\end{array}$ \\
\hline$c m$ & & & & & \\
$30.5 \ldots \ldots \ldots \ldots$ & -0.2431 & -0.1887 & 0.3738 & 0.4467 & 20 \\
$61.0 \ldots \ldots \ldots \ldots$ & 0.1099 & 0.2357 & 0.5508 & 0.6664 & 20 \\
$91.4 \ldots \ldots \ldots \ldots$ & 0.1553 & 0.4067 & 0.5184 & 0.7243 & 20 \\
$121.9 \ldots \ldots \ldots \ldots$ & 0.0997 & 0.4094 & 0.5864 & 0.8134 & 20 \\
$152.9 \ldots \ldots \ldots \ldots$ & 0.1282 & 0.3723 & 0.3855 & 0.5567 & 20 \\
$182.9 \ldots \ldots \ldots$ & 0.0153 & 0.2479 & 0.3570 & 0.5548 & 20 \\
\hline
\end{tabular}

centage of saturation may well serve as an indicator of the effective area through which water is conducted. Usually, hydraulic conductivity measurements are made as a function of soilwater content on a volume basis without any knowledge of the percentage of saturation. This study shows that both are important, especially when the soil properties vary spatially.

Although the reasons are not readily apparent, examination of tables 11,12 , and 13 reveals that the flow characteristics of this 150-hectare field are most closely correlated with properties of the soil between 91.4 and $121.9 \mathrm{~cm}$. The present field was cut, filled, and graded before farming began. Although no distinctive, well-defined horizon has been observed in the soil profile, this study clearly shows that the 91.4 to $121.9-\mathrm{cm}$ depth is important in determining how water flows through the soil profile. Thus, it is supposed that for a naturally developed field soil there may be a particular horizon whose physical properties should dictate the soil-water transport characteristics. Accumulation of knowledge on what is the most appropriate layer to use for simplified approaches on various types of soil would be most helpful in predicting soil-water behavior.

\section{Hydraulic conductivity}

We have discussed two alternatives for evaluating the spatial variation of hydraulic conductivity. First, by representing the hydraulic conductivity as a function of percentage of saturation, we were able to estimate the variation of hydraulic conductivity with respect to any specific percentage of saturation. It is obvious from table 5 that gen- 
erally the coefficient of variation of hydraulic conductivity increases irith decreasing percentage of saturation. The spatial variation of the soil-physical properties at the $30.5-\mathrm{cm}$ depth is largest among the six different depths. This reflects the spatial variation of the hydraulic conductivity at the 30.5cm depth. The coefficient of variation ranges from about 100 per cent at saturation to about 400 per cent at 54 per cent of saturation. Coefficients of variation of hydraulic conductivity for the other five depths range from less than 100 to about 300 per cent. For the over-all average, which includes horizontal as well as vertical variation, coefficients of variation ranges from 85 per cent at saturation to 450 per cent at 54 per cent saturation.

In the second method we regard the field as a homogeneous soil mass, and we treat soil-water content and hydraulic conductivity as two separate experimental variables which would be measured from time to time. Thus, at each individual depth we will have 20 replications in terms of soil-water content and hydraulic conductivity. For the six depths, we would obtain 120 values of water content and hydraulic conductivity at any particular time period. Using this approach of averaging the soil-water content and the hydraulic conductivity at incremental time periods, the data in table 7 and figure 14 were obtained. These data represent the mean hydraulic conductivity-water content relationship for the entire field.

$$
F\left(x^{\prime}, y^{\prime}\right)=\frac{1}{2} \pi \iint \exp \left[-\left(x^{\prime 2}+y^{\prime 2}\right) / 2\right] d x^{\prime} d y^{\prime}
$$

Next we introduce two new variables $x$ and $y$ which are correlated and are normally distributed. We relate $x, y$, and $x^{\prime}, y^{\prime}$ by the following equations

$$
\begin{gathered}
x=m_{1}+\sigma_{1} x^{\prime} \\
y=m_{2}+r \sigma_{2} x^{\prime}+\sqrt{1-r^{2}} \sigma_{2} y^{\prime}
\end{gathered}
$$

Equations [35] and [36] are so arranged that the new variables $x$ and

\section{Soil-water flux}

In the application of equation [17], it is clear that both the steady-state hydraulic conductivity $K_{o}$ and the slope $\alpha$ of equation [15] play important roles. Suppose we know the values of the steady-state water content $\theta_{0}$ and $K_{o}$, and that we have knowledge of the soil-water characteristic. Then, using the method of Childs and CollisGeorge or that of Millington and Quirk, we can calculate the relation of $K(\theta)$, and thus evaluate the value of $\alpha$ at $\left(K_{o}, \theta_{o}\right)$.

Considering the spatial variability of the entire field, the question arises: For an average value of the soil-water content and its standard deviation, what is the corresponding mean value of the hydraulic conductivity and its standard deviation? We have worked out the answer for only the steadystate values of the hydraulic conductivity and soil-water content. We found that the steady-state water content $\theta_{o}$ was normally distributed (equation [32]) and that the value of $K_{o}$ was log-normally distributed (equation [33]). The correlation coefficient of $\theta_{o}$ and $\ln K_{o}$ was 0.327 , which is significant at the 1 per cent level for 120 samples.

In order to determine for any particular $\theta$ (in the case of steady state, $\theta=\theta_{o}$ ) what is the corresponding value of $K$ (in the steady state case, $K=K_{o}$ ) and its variation, let us consider two independent variables $x^{\prime}$ and $y^{\prime}$, each of which is normal $(0,1)$, their joint distribution function is

$y$ have the means $m_{1}$ and $m_{2}$, the standard deviations $\sigma_{1}$ and $\sigma_{2}$, and the correlation coefficient $r$. Rearranging equations [35] and [36], we obtain

$$
x^{\prime}=\left(x-m_{1}\right) \sigma_{1}^{-1}
$$

$y^{\prime}=\frac{1}{\sqrt{1-r^{2}}}\left[-r\left(\frac{x-m_{1}}{\sigma_{1}}\right)+\frac{y-m_{2}}{\sigma_{2}}\right]$ 
Equation [34] as a function of the new variables becomes

$$
F(x, y)=\frac{1}{2 \pi} \iint D \exp [-Q(x, y) / 2] d x d y
$$

where

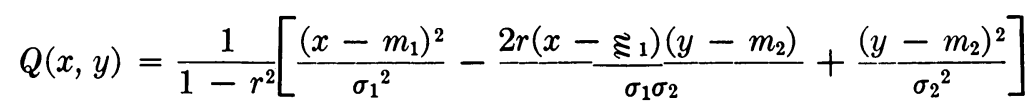

and $D$ is the Jacobian

$$
D=\left|\begin{array}{ll}
\frac{\partial x^{\prime}}{\partial x} & \frac{\partial x^{\prime}}{\partial y} \\
\frac{\partial y^{\prime}}{\partial x} & \frac{\partial y^{\prime}}{\partial y}
\end{array}\right|
$$

The joint frequency function of $x$ and $y$ according to (Cramer, 1955) is

$$
f(x, y)=\frac{1}{2 \pi \sigma_{1} \sigma_{2} \sqrt{1-r^{2}}} \exp [-Q(x, y) / 2]
$$

Equation [40] is the general form of the two-dimensional normal frequency function. If we denote $x=\ln z$, then equation [40] becomes

$$
f(z, y)=\frac{1}{2 \pi \sigma_{1} \sigma_{2} z \sqrt{1-r^{2}}} \exp [-Q(x, y) / 2]
$$

where

$$
Q(z, y)=\frac{1}{1-r^{2}}\left[\frac{\left(\ln z-m_{1}\right)^{2}}{\sigma_{1}{ }^{2}}-\frac{2 r\left(\ln z-m_{1}\right)\left(y-m_{2}\right)}{\sigma_{1} \sigma_{2}}+\frac{\left(y-m_{2}\right)^{2}}{\sigma_{2}{ }^{2}}\right]
$$

As shown earlier, the steady-state hydraulic conductivity $K_{o}$ is log-normally distributed. Rewriting equation [33] in terms of $K_{o}$ and choosing $\beta=0$, we have

$$
f_{1}\left(K_{o}\right)=\frac{1}{\sigma_{1} K_{o} \sqrt{2 \pi}} \exp \left[\frac{-\left(\ln K_{o}-m_{1}\right)^{2}}{2 \sigma_{1}{ }^{2}}\right]
$$

Similarly, because the steady-state water content $\theta_{0}$ is normally distributed we rewrite equation [32] in terms of $\theta_{\mathrm{o}}$

$$
f_{2}\left(\theta_{o}\right)=\frac{1}{\sigma_{2} \sqrt{2} \bar{\pi}} \exp \left[\frac{-\left(\theta_{o}-m_{2}\right)^{2}}{2{\sigma_{2}}^{2}}\right]
$$

Their joint distribution function according to equation [41] is

$$
f\left(K_{o}, \theta_{o}\right)=\frac{1}{2 \pi \sigma_{1} \sigma_{2} K_{o} \sqrt{1-r^{2}}} \exp \left[-Q\left(K_{o}, \theta_{o}\right) / 2\right]
$$

where

$$
Q\left(K_{o}, \theta_{o}\right)=\frac{1}{1-r^{2}}\left[\frac{\left(\ln K_{o}-m_{1}\right)^{2}}{\sigma_{1}{ }^{2}}-\frac{2 r\left(\ln K_{o}-m_{1}\right)\left(\theta_{o}-m_{2}\right)}{\sigma_{1} \sigma_{2}}-\frac{\left(\theta_{o}-m_{2}\right)^{2}}{\sigma_{2}{ }^{2}}\right]
$$


Then the conditional frequency function of the steady-state hydraulic conductivity relative to any other value of

$$
\frac{f\left(K_{o}, \theta_{o}{ }^{\prime}\right)}{f_{2}\left(\theta_{o}^{\prime}\right)}=\frac{1}{\sqrt{2 \pi} \sigma_{1} K_{o} \sqrt{1-r_{2}}} \exp \left[\frac{-\left[\ln K_{o}-m_{1}-\frac{r \sigma_{1}}{\sigma_{2}}\left(\theta_{o}{ }^{\prime}-m_{2}\right)^{2}\right]}{2 \sigma_{1 o}\left(1-r_{o}\right)}\right]
$$

Equation [45] is a normal frequency function in $K_{o}$ (steady-state hydraulic conductivity) with the mean value

$m_{3}=m_{1}+r \sigma_{1}\left(\theta_{o}^{\prime}-m_{2}\right) \sigma_{2}^{-1}$

and standard deviation

$$
\sigma_{3}=\sigma_{1} \sqrt{1-r^{2}}
$$

If we denote $\epsilon$ as the arithmetic mean of $K_{o}$ and $\tau$ its corresponding standard deviation, then the following relations are established (Johnson and Leone, 1964):

$$
\begin{gathered}
\epsilon=\exp \left[m_{3}+\sigma_{3}^{2} / 2\right] \\
\tau=\exp \left[m_{3}+\sigma_{3}^{2} / 2\right] \sqrt{\exp \left(\sigma_{3}^{2}-1\right)}
\end{gathered}
$$

another steady state water content $\theta_{o}$ is the following:
Applying equations [45], [46], [47], [48], and [49] we are able to estimate the mean and standard deviation of the steady-state hydraulic conductivity relative to any given soil-water content based on the distributions depicted in figures 10 and 16 . Table 14 gives a comparison between calculated and measured values of the mean and standard deviation of $K_{o}$ for the six different depths.

The statistical approach briefly given above should be an appropriate method in any kind of field study. From table 14, we know that at a depth of $182.9 \mathrm{~cm}$ the average value of $\theta_{0}$ is $0.458 \mathrm{~cm}^{3} \mathrm{~cm}^{-3}$ corresponds to a

TABLE 14

MEAN STEADY-STATE WATER CONTENT $\theta^{\prime}$. VERSUS MEASURED AND

\begin{tabular}{|c|c|c|c|c|c|}
\hline $\begin{array}{c}\text { Soil } \\
\text { depth }\end{array}$ & $\theta_{0}$ & Measured & Calculated & Measured & Calculated \\
\hline $30.5 \ldots \ldots$ & 0.397 & 14.74 & 17.12 & 17.69 & 20.41 \\
\hline $61.0 \ldots$ & 0.409 & 15.05 & 18.40 & 16.22 & 21.92 \\
\hline $121.9 \ldots$ & 0.446 & 18.27 & 22.66 & 18.65 & 27.00 \\
\hline $152.4 \ldots$ & 0.446 & 22.64 & 22.67 & 23.59 & 27.01 \\
\hline $182.9 \ldots \ldots$ & 0.458 & 26.16 & 24.24 & 30.75 & 28.88 \\
\hline average........ & 0.429 & 20.62 & 20.53 & 24.73 & 24.46 \\
\hline
\end{tabular}
CALCULATED (EQUATIONS [48] AND [49]) MEAN STEADY-STATE HYDRAULIC CONDUCTIVITY $\epsilon$ AND ITS STANDARD DEVIATION OF THE MEAN $\tau$

calculated average value of $K_{o}$ equal to $26.2 \mathrm{~cm} \mathrm{day}^{-1}$. Utilizing this pair of values as a matching factor for the Millington and Quirk method, theoretical values of $K$ verses $\theta$ are available. Figure 24 shows the calculated and measured values of $K(\theta)$ at the 182.9-cm depth. The open circles designate the experimental data and the solid line represents the calculated values. The square symbol designates the matching point $\left(K_{o}, \theta_{0}\right)$. The value 


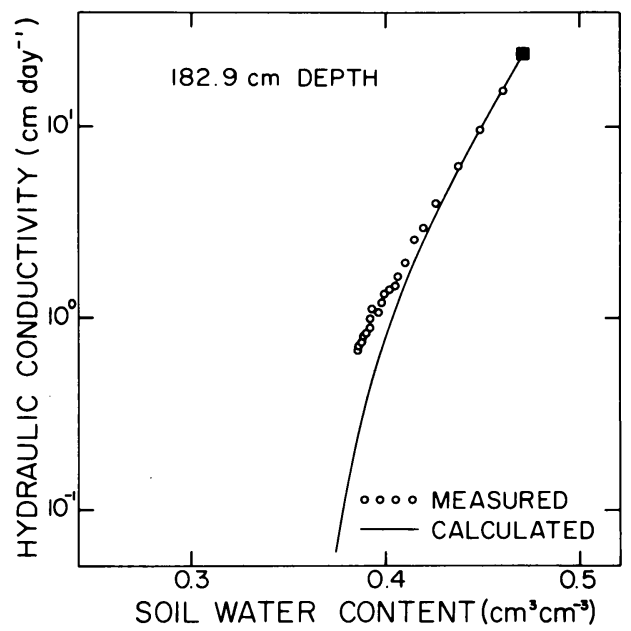

Fig. 24. Data points are measured values of the hydraulic conductivity as a function of soll. water content for the 182.9-cm depth averaged over the entire field. The solid line depicts values calculated by the Millington and Quirk method using the matching factor $\left(\boldsymbol{K}_{o}, \boldsymbol{\theta}_{o}\right)$ equal to $\left(26.2 \mathrm{~cm} \mathrm{day}^{-1}, 0.458 \mathrm{~cm}^{3} \mathrm{~cm}^{-3}\right)$. Circles designate experimental values. Square indicates matching point.

of $\alpha$ for the measured function $K(\theta)$ at the $182.9-\mathrm{cm}$ depth is 44.0 . The slope of the solid line at the point represented by the solid square is 43.2 which we regard as an approximation of $\alpha$. Now we have one set of average $K_{o}$ and $\alpha$ obtained from experimental data and the other set of average $K_{o}$ and $\alpha$ derived from equation [48] and $K(\theta)$ stemming from the Millington and Quirk method. From these two sets of $K_{o}$ and $\alpha$ the two theoretical soil-water flux curves from equation [17] are

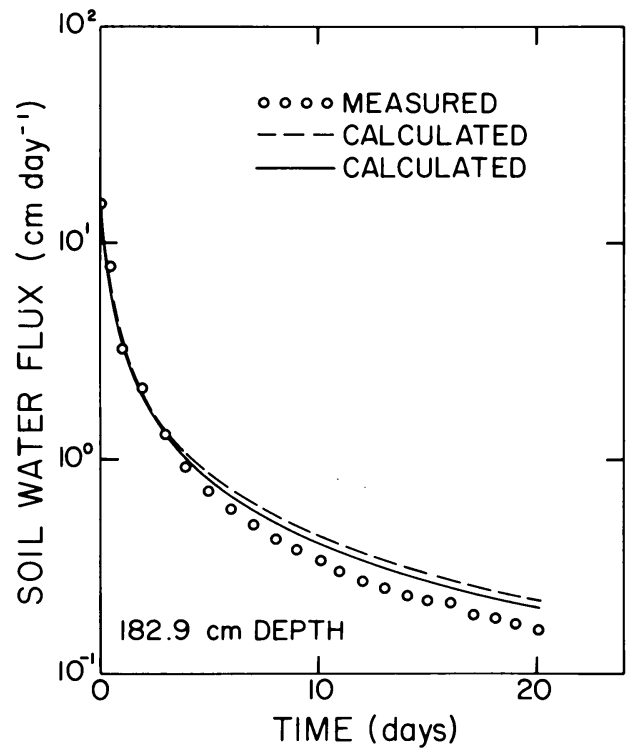

Fig. 25. Average soil-water flux at the $\mathbf{1 8 2 . 9}$ $\mathrm{cm}$ depth as a function of time following the cessation of infiltration. The solid line stems from equation [17] using values of $K_{0}$ and $\alpha$ stemming from the measured values of $K(\theta)$ given in figure 14. The broken line stems from values of $K_{o}$ and $\alpha$ estimated by the calculated values of $K(\theta)$ shown in figure 24 at the point $\left(\boldsymbol{K}_{o}, \theta_{o}\right)$.

given in figure 25 together with the average measured soil-water for the $182.9 \mathrm{~cm}$ depth. The solid line is the result of measured values of $K_{o}$ and $\alpha$ and the broken line stems from estimated values of $K_{o}$ and $\alpha$. Allowing for the values of standard deviation shown in table 9, there is good agreement between the two theoretical curves and the experimental data for this depth and others not shown.

\section{CONCLUSIONS AND SUMMARY}

The field studied, which was typical of fields in areas of irrigated agriculture, had been graded for efficient production. Although no distinctive welldefined horizon exists throughout the soil profile, it appears from our study that the physical properties at the 120 -cm depth are especially important to the over-all hydraulic characteristics of the soil. For a naturally developed, well-defined soil profile with distinct horizons there will probably be certain horizons which would more or less govern soil-water movement. The physical properties of such a horizon should be extensively studied.

The 150-hectare field studied is fairly uniform in soil classification. 
The spatial variation of some of its physical properties (i.e., particle size distribution and bulk density) is well within the permitting limit of a mapping unit (Beckett and Webster, 1971), whereas the steady infiltration rate varied considerably from one plot to another. The steady infiltration rate ranged from 0.5 to $45.7 \mathrm{~cm} \mathrm{day}^{-1}$. In terms of the steady hydraulic conductivities, the range was even largerfrom about $10^{-1}$ to (roughly) $10^{2} \mathrm{~cm}$ day $^{-1}$. Recalling that the location and the steady state infiltration value of all 20 experimental plots within the 150-hectare field are given in figure 1 , it seems that the field can be roughly subdivided into three units according to the steady infiltration rate. Unit (1) would consist of plots $5,7,8$, and 20 ; unit (2) would be plots $1,3,4,6$, $9,10,11,12$, and 15 ; unit (3) would be plots $13,14,16,17$, and 18 . In order to provide more accurate and useful information it may be practical to include the steady state infiltration rate as one of the criterion used in soil classification. Because the steady state infiltration rate was found to be exponentially related to percentage of water saturation, it would be more sensitive than any measure of soilwater content.

We have presented two different ways to evaluate the spatial variability of hydraulic conductivity. First, we presented hydraulic conductivity as a function of percentage of water saturation so that all the hydraulic conductivity versus per cent saturation curves would fall into the limit of per cent saturation between 0 and 100 per cent. The spatial variation of hydraulic conductivity increases with decreased per cent saturation. Secondly, we visualize the field as a homogeneous soil mass and regard soil-water content and hydraulic conductivity as two variables which could be measured separately. At each depth, 20 measurements of soil-water content and hydraulic con- ductivity were available. Or, at all depths, 120 pairs of values were available for each time period to calculate the mean value and standard deviation of both soil-water content and hydraulic conductivity (fig. 15). Using the information provided by figure 5 , equation [17] was successfully applied to predict the soil-water flux at six different depths (fig. 23).

If sufficient information about $K(\theta)$ is not available and only the distributions of $K_{o}$ and $\theta_{\mathrm{o}}$ are known, Millington and Quirk's method (1960) can generate the necessary information about $K(\theta)$ in order to apply equation [17].

It is believed that the statistical approach presented in this text will be applicable to areas larger than the 150 hectare field, provided sufficient information about soil-water characteristies and $K(\theta)$ are available.

As a consequence of this study we conclude:

1. Variations in water content are normally distributed with depth and with horizontal distance throughout the field, while values of hydraulic conductivity and soil-water diffusivity are log-normally distributed.

2. A simple equation can be used to predict the flux of water leaving any desired depth of soil as a function of time following infiltration. The equation requires only that the steadystate hydraulic conductivity and the slope of the hydraulic conductivitywater content curve near saturation be known.

3. Methods available in the literature for predicting hydraulic conductivity versus soil-water content relations from -soil-water characteristic curves are adequate for predicting field values.

4. Simplified methods for measuring field values of hydraulic conductivity or soil-water diffusivity, using simply a single or preferabley two tensiometers and a reliable soil-water. 
characteristic curve, are sufficiently accurate for characterizing field conditions.

5. Even seemingly uniform land areas manifest large variations in hydraulic conductivity values. Variations in texture, bulk density, and water content are much less. For a given location, methods for measuring water content, hydraulic conductivity, and hydraulic gradients will yield values that are much more accurate than required to characterize an entire field because of the heterogeneity of the soil. Thus, our ability to make predictions over a large area from a single plot can range from good to unsatisfactory, depend- ing on the particular prediction parameter of interest.

6 . The lack of correlation between soilwater parameters and soil-bulk density or particle size implies that measurements made historically during soil surveys have limited value for predicting soil-water movement and retention.

7. The most important laboratory measurements for predicting soil-water behavior in the field are the soilwater characteristic curve and a steady-state hydraulic conductivity value. These measurements provide ample information with which to approximately predict the behavior of soil water under field conditions.

\section{ACKNOWLEDGMENTS}

The main impetus for this study of water movement under field conditions came from the U. S. Bureau of Reclamation, and particularly through the interest of $\mathrm{Mr}$. John Maletic who wished to predict the behavior of nitrogen in field soils.

Countless hours, days, and months of unstinted effort ranging from mundane tasks of recording hourly measurements through the night to academic considerations of statistical and physical analyses were committed to this experiment by many persons. Without their help, our experiment would not yet be completed. We wish to especially acknowledge the leadership of Robert K. Jackson, Dennis E. Rolston, and James MacIntyre during measurement phases, and the conceptual and analytical contributions made by Robert J. Miller and John C. Corey. We are also appreciative of the efforts of William Moore, Douglas Airhart, Charles Krauter, David Goldhamer, Jeff Wagenet, Cevat Kirda, and dozens of other students with whom we have shared responsibility of implementing and completing this effort.

The financial support of the Bureau of Reclamation, Cooperative States Research Service, the Kearney Foundation of Soil Science, the California Department of Water Resources, and the Federal Water Quality Control Agency is gratefully acknowledged. Use of the facilities of the West Side Field Station of the University of California, and the cooperation of J. L. Myler and Richard Hoover, and the assistance of field station personnel, are acknowledged.

\section{LITERATURE CITED}

ANDrew, L. E., and W. R. Sterns

1963. Physical characteristics of four Mississippi soils. Proc. Soil Sci. Soc. Amer. 27:693-97.

BECKeTt, P. H. T., and R. WEBSTER

1971. Soil variability: A review. Soils and Fertilizers 34:1-15.

Black, T. A., W. R. Gardener, and G. W. Thurtell

1969. The prediction of evaporation drainage and soil water storage for a bare soil. Soil Sci. Soc. Amer. Proc. 33:655-60. 
Bruce, R. R., and A. KLute

1956. The measurement of soil water diffusivity. Soil Sci. Soc. Amer. Proc. 20:458-62.

Childs, E. C., and N. Collis-George

1950. The permeability of porous materials. London: Proc. Roy. Soc. A:201:392-405.

CRAMER, $\mathrm{H}$.

1955. The elements of probability theory and some of its application. New York: J. Wiley and Sons, Inc. 281 pages.

Davidson, J. M., L. R. Stone, D. R. Nielsen, and M. E. La Rue

1969. Field measurement and use of soil-water properties. Water Resources Research 5:1312-21.

Day, Paul R.

1965. Particle fractionation and particle-size analysis. IN C. A. Black, Editor-in-Chief, ERH, K. T. Methods of soil analysis, Agronomy Monograph 9:545-67.

1972. Application of spline function to soil science. Soil Science 114:333-38.

GARDNER, W. R.

1956. Calculation of capillary conductivity from pressure plate outflow data. Soil Sci. Soc. Proc. Amer. Proc. 20:317-20.

Hammond, L. C., W. L. Prichett, and V. Chew

1958. Soil sampling in relation to soil heterogeneity. Soil Sci. Soc. Amer. Proc. 22:548-52.

Jackson, R. D., R. J. Reginato, and C. H. M. Van Bavel

1965. Comparison of measured and calculated hydraulic conductivities of unsaturated soils. Water Resources Res. 1:375-80.

JACOB, W. C., and A. KLUTE

1965. Sampling soils for physical and chemical properties. Soil Sci. Soc. Amer. Proc. 20:170-72.

Johnson, N. L., and F. C. Leone

1964. Statistics and experimental design in engineering and the physical science, Vol I. New York: John Wiley and Sons, Inc.

KLute, A.

1965. Laboratory measurement of hydraulic conductivity of saturated soil. IN C. A. Black, Editor-in-Chief, Methods of soil analysis, Agronomy Monograph 9:253.61.

Kunze, R. J., G. Uehara, and K. Graham

1968. Factors important in the calculation of hydraulic conductivity. Soil Sci. Soc. Amer. 32:760-765.

LaRue, M. E., D. R. Nielsen, and R. M. Hagan

1968. Soil water fiux below a ryegrass root zone. Agron. J. 60:625-29.

Marshall, T. J.

1958. A relation between permeability and size distribution of pores. J. of Soil Sci. 9:1-8.

Mason, D. D., J. F. Lutz, and R. G. Petersen

1957. Hydraulic conductivity as related to certain soil properties in a number of great soil groups sampling errors involved. Proc. Soil Sci. Soc. Amer. Proc. 21:554-60.

MCINTyre, D. S., and C. B. TANNER

1959. Abnormally distributed soil physical measurements and nonparametric statistics. Soil Sci. 88:133-37.

Miller, D. E., and J. S. Aarstad

1972. Estimating deep drainage between irrigations. Soil Sci. Soc. Amer. Proc. 36:124-27.

Millington, R. J., and J. P. QUIRK

1959. Permeability of porous media. Nature 183:387-88.

1960. Transport in porous media. Intl. Congr. Soil Sci., Trans. 7th (Madison, Wis.) 13:97106.

1961. Permeability of porous solids. Trans. Faraday Soc. 57:1200-07.

Nielsen, D. R., and J. W. BigGaR

1961. Measuring capillary conductivity. Soil Sci. 92:192-93.

Nielsen, D. R., J. M. Davidson, J. W. Biggar, and R. J. Miller

1964. Water movement through Panoche clay loam soil. Hilgardia 35:491-506.

Nielsen, D. R., D. Kirkham, and E. R. Perrier

1960. Soil capillary conductivity comparison of measured and calculated values. Soil Sci. Soc. Amer. Proc. 24:157-60.

NiELSEN, D. R., D. KiRKhAM, and W. R. VAN WiJK

1961. Diffusion equation calculations of field soil water infiltration profiles. Soil Sci. Soc. Amer. Proc. 25:165-68. 
Ogata, Gen, and L. A. Richards

1957. Water content changes following irrigation of bare-field soils and its effect on soil moisture investigations. Soil Sci. Soc. Amer. Proc. 18:344-47.

Richards, L. A., W. R. Gardner and G. Ogata

1956. Physical processes determining water loss from soil. Soil Sci. Soc. Amer. Proc. 20:310-14.

Robins, J. S., W. O. Pruitt and W. H. GARdNer

1954. Unsaturated flow of water in field soils and its effect on soil moisture investigations. Soil Sci. Soc. Amer. Proc. 18:344-47.

Rose, C. W., W. R. STERN and J. E DRummond

1965. Determination of hydraulic conductivity as a function of depth and water content for soil in situ. Aust. J. Soil Res. 3:1-9.

RUBIN, J.

1967. Numerical method for analyzing hysteresis affected post-infiltration redistribution of soil moisture. Soil moisture. Soil Sci. Soc. Amer. Proc. 31:13-20.

Sharma, M. L.

1966. Influence of soil structure on water retention water movement and thermodynamic properties of adsorbed water. Ph.D. thesis, Univ. of Hawaii. 190 pp. Univ. Microfilms. Ann Arbor, Mich. (Diss. Abst. 28, 1960-b, 1967).

Shaw, R. H., D. R. Nielsen and J. R. Runkles

1959. Evaluation of some soil moisture characteristics of Iowa soils. Iowa Agricultural Expt. Sta. Res.

WANG, F. C. and W. Lakshiminarayana

1968. Mathematical simulation of water movement through unsaturated nonhomogeneous soils. Soil Sci. Soc. Amer. Proc. 32:329-34.

Wilcox, J. C.

1960. Rate of soil drainage following an irrigation. II. Effects on determination of rate of consumptive use. Canad. J. Soil Sci. 40:15-27. 
